\title{
A sustainable second-generation biodiesel supply chain network design problem under risk
}

\author{
Reza Babazadeh $^{\mathrm{a}}$, Jafar Razmi ${ }^{\mathrm{a}, *}$, Mir Saman Pishvaee ${ }^{\mathrm{b}}$, Masoud Rabbani ${ }^{\mathrm{a}}$ \\ ${ }^{a}$ School of Industrial Engineering, College of Engineering, University of Tehran, Tehran, Iran \\ ${ }^{b}$ School of Industrial Engineering, Iran University of Science and Technology, Tehran, Iran
}

\begin{abstract}
This paper presents a multi-objective possibilistic programming model to design a second-generation biodiesel supply chain network under risk. The proposed model minimizes the total costs of biodiesel supply chain from feedstock supply centers to customer centers besides minimizing the environmental impact (EI) of all involved processes under a well-to-wheel perspective. Non-edible feedstocks are considered for biodiesel production. Variable cultivation cost of non-edible feedstock is assumed to be non-linear and dependent upon the amount of cultivated area. New formulation of possibilistic programming method is developed which is able to minimize the total mean and risk values of problems with possibilistic-based uncertainty. To solve the proposed multi-objective model, a hybrid solution approach based on flexible lexicographic and augmented $\varepsilon$-constraint methods is proposed which is capable to find appropriate efficient solutions from the Pareto-optimal set. The performance of the proposed possibilistic programming method as well as the developed solution approach are evaluated and validated through conducting a real case study in Iran. The outcome of this study demonstrates that high investment cost is required for improving the environmental impact and risk of sustainable biodiesel supply chain network design under risk. Decision maker preferences are required for suitable trade-off among total costs, risk values and environmental impact.
\end{abstract}

Keywords: Sustainable development; Second-generation biodiesel supply chain; Non-edible feedstock;

Possibilistic programming; Multi-objective optimization.

\section{Introduction}

Recently, biofuel demand for transportation sector has been intensively increased due to energy crisis, environmental and social concerns. Among the different sectors demanding energy, transportation has the largest share in energy demand [1]. Biodiesel is a type of biofuel combined with fossil-based diesel in different percentages is mostly used in transportation sector [2]. Although first generation biofuels production has been commercialized at worldwide, there is a significant concern about food crisis by extending first generation biofuels feedstock [3]. First

\footnotetext{
* Corresponding author. Tel.: +98 21 88021067; fax: +98 2188013102.

E-mail address: jrazmi@ut.ac.ir (J. Razmi).
} 
generation biofuels are unsustainable due to competition with food resources [4]. On the other hand, second generation biofuels are environmentally and socially sustainable and do not compete with food resources [3]. However, economic sustainability of both first and second generation biofuels is still under debate [4]. Therefore, researchers are highly engaged to find the ways improving the commercial feasibility of second generation biofuels production. Jatropha curcas L. (JCL) has been known as the most promising non-edible energy crop for producing second generation biodiesel $[4,5]$. JCL seed kernel has high oil content circa $30-40 \%$ and its oil content is ranked second after palm among edible and non-edible energy crops [6]. The main contributions of JCL making it to be superior to other non-edible energy crops include [5, 6, 7]: (1) growth in marginal lands and soil reclamation, (2) preventing soil erosion and improving water infiltration, (3) drought tolerant and low water and nutrient requirement, (4) reduction of greenhouse gas emission, (5) opportunity for rural development and contribution to poverty reduction, (6) useful by-products used as manure, hygienic and medicinal material production, and (7) high resistance against pests and diseases. According to the JCL belt $\left(30^{\circ} \mathrm{N}, 35^{\circ} \mathrm{S}\right)$ indicating the most suitable areas for JCL cultivation at worldwide, most of Asian countries have the most suitable weather and soil conditions for JCL cultivation. Some real case studies in Malaysia, Indonesia, and India show commercial feasibility of JCL projects in these countries [8, 9, 10]. Another non-edible oil for biodiesel production is used cooking oil (UCO). An appropriate planning for collecting UCO solves its disposal problems and provides biodiesel feedstock with very low price [11].

Nowadays, in all industries, traditional economic development has been replaced by sustainable development guaranteeing economic development besides environmental and social improvement [12]. Sustainable development has been interested in strategic, tactical and operational levels of supply chain planning decisions [13]. Since supply chain (SC) activities involve all the tiers from raw material suppliers to end products retailers in an integrated scheme, SC planning decisions have significant environmental and social impacts [14]. The sustainable design of a SC involves improving the environmental and social impacts besides economic aspects in all relevant activities including facility establishment, production, inventory holding and transportation [15]. Life cycle assessment (LCA) is a well-known method used by environmental experts to assess the environmental impact of different industries [16]. Since employing LCA method in each industry is a complex task and needs environmental experts, 
recently some LCA-based quantitative methods such as Eco-indicator 99 [17], IMPACT 2002+ [18], and ReCiPe 2008 [19] have been developed to allow the researchers in different fields to conveniently estimate environmental impact of different industries [20].

In this paper, an integrated mixed-integer non-linear programming (MINLP) model is developed to design a second-generation biodiesel SC network under risk. The proposed MINLP model is then transformed to its equivalent mixed-integer linear programming (MILP) form through efficient linearization techniques. The developed model minimizes the environmental impact (EI) of all involved processes in the considered biodiesel SC network besides minimizing the net present value (NPV) of related total costs subject to real-life assumptions and constraints. Variable cultivation costs of JCL are dependent upon the amount of cultivated area and vary as a piecewise function. Non-edible JCL seed oils and UCOs are considered as feedstock to produce second-generation biodiesel. The model is developed under uncertainty of feedstock supply, biodiesel and glycerin demands in constraints, cost and environmental coefficients in the objective functions (OFs). Due to lack of reliable historical data about the uncertain parameters, possibilistic-based uncertainty is used to model the uncertain behavior of parameters. According to [14], Possibilistic programming approach that uses subjective and objective data is the most appropriate tool to deal with the ambiguity of parameters when there is no enough historical data. It should be noted that biofuel SCs are more vulnerable to risk respect to traditional SCs because of the fact that price of feedstock and biodiesel is influenced by the price of crude oil and agriculture products [21, 22]. Also, the amount of JCL yields is dependent upon weather conditions which are unpredictable in long term period. To handle the uncertainty of the model, a new formulation of possibilistic programming method is presented which is capable to minimize the mean and risk values of the considered OFs. To solve the proposed multi-objective possibilistic biodiesel supply chain network design (MO-PBSCND) model a hybrid solution method based on flexible lexicographic and augmented $\varepsilon$-constraint methods is presented to find appropriate efficient solutions from the Pareto-optimal set. Finally, the proposed MO-PBSCND model and solution procedures are justified through conducting a real case study in Iran.

The remainder of this paper is organized as follows. In the next section, the relevant literature is reviewed. In Section 3, the concerned problem is described and formulated. The new formulation of possibilistic programming method based on possibilistic mean and absolute deviation is presented in Section 4 and the proposed solution method is elaborated in Section 5. The studied 
case and acquired results and discussions are described in Section 6. Finally, conclusions of the study and some future research directions are presented in Section 7.

\section{Literature review}

Among liquid biofuels, the bioethanol and biodiesel SCs are studied by researchers and practitioners more than the other types. Since about $80 \%$ of total biofuel production costs is related to feedstocks [23], most of biofuel SC optimization models have focused on optimizing upstream sections, i.e., from feedstock supply centers to bio-refineries [22]. However, to escape from sub-optimal solutions it is critical to integrate upstream and downstream sections of biofuel SCs.

Most of the studies in literature have been dedicated to developing biofuel SC models under deterministic conditions with the aim of economic OF optimization (cost minimization or profit maximization). Papapostolou et al. [24] developed a classical model for optimizing capacity of established facilities, material flows and import-export decisions in a biodiesel SC network design problem. Troncosoa and Garrido [25] presented a multi-period MILP model for optimizing capacity of facilities and material flows in a bioethanol SC subject to harvesting and forest-area constraints. $\mathrm{Ng}$ et al. [26] evaluated centralized and decentralized rubber seed processing facilities in a biodiesel SC network design problem. In their work, crude palm oil and rubber seed oil are investigated in terms of environmental impact, feedstock price and energy consumption and then the optimal blends of these feedstocks are determined through sensitivity analysis. Rentizelas et al. [27] stated that feedstock supply costs constitute the major share of biofuel total production cost and therefore its minimization should be integrated with other related costs. According to their study and due to seasonal availability of feedstock, inventory holding decisions should be considered in biofuel SC models over different periods to guarantee continuous production of biofuels in upcoming periods. Rentizelas and Tatsiopoulos [28] presented a hybrid optimization method based on simulation and mathematical programing methods to locating bioenergy facilities. Akgul et al. [29] developed a multi-objective model to optimize both economic and environmental objectives of a hybrid first/second generation bioethanol supply chain. Huang et al. [30] proposed a multi-stage optimization model to determine location and capacity of bio-refineries and material flow in a biofuel SC optimization. 
Ebadian et al. [31] extended a MILP model for optimizing upstream section of a bioethanol SC network. They consider two types of storage centers including roadside and satellite storage.

A thin part of the literature in biofuel SC modeling have been dedicated to sustainable design of biofuel SCs with the aim of considering environmental impact and social issues in strategic and tactical level decisions besides economic aspect considerations. Giarola et al. [32] presented a bioethanol SC network design model with the aim of cost and $\mathrm{Co}_{2}$-eq minimization. Ecoindicator 99 method is used for calculating $\mathrm{Co}_{2}$-eq of different processes. Giarola et al. [33] extended their previous work by considering downside risk measure to reduce the risk resulted from uncertain parameters. Liu et al. [34] presented a MILP model for optimizing economic, energy, and environmental objectives in a biofuel SC network design problem. Energy objective is measured by the fossil energy input per mega joule of biofuel production. Santibañez-Aguilar et al. [35] developed a MILP model for designing hybrid biodiesel and bioethanol SC network incorporating economic, environmental and social OFs. Eco-indicator 99 is used for measuring EI and number of created jobs is used for measuring the social objective. The proposed triple OFs model is solved by $\varepsilon$-constraint method.

A number of researchers have dealt with the uncertainty of feedstock supply, biofuel demand, and different costs in their problems. The seminal work in dealing with the uncertainty of biofuel SCs is the work [36] that uses two-stage stochastic programming (SP) method to model uncertain weather conditions influencing the amount of swithgrass feedstock yield in cultivation phase. Osmani and Zhang [37] used two-stage SP method to deal with the uncertainty of feedstock supply, biofuel demand, buying and selling price in biofuel SC design. Dal-Mas et al. [38] developed a multi-period MILP model for biofuel SC design under uncertainty of costs and price. They employed SP method to deal with the uncertainty of such problem. Gonela et al. [39] proposed a stochastic MILP model to design industrial symbiosis based hybrid generation bioethanol supply chains. In their model, total profit is maximized subject to limitation of total amount of GHG emissions and other logic constraints. Some other relevant studies in this field are models studied in [21, 40, 41].

It should be noted that using SP methods to deal with the uncertainty of biofuel SCs needs reliable historical data and also this approach increases computational complexity of these problems [42]. Therefore, applying SP approach in real-life large cases may be impossible. Additionally, the literature suffers from lack of integrated models for sustainable design of 
second-generation biofuel SC under real assumptions. For example, in the current literature nearly all studies assume cultivation and production costs to be varied in a linear form while these costs dependent upon the amount of cultivated area and production amount in real world practices. Also, the existing models focus on EI assessment in production and distribution sections of biofuel SCs while EI should be assessed under well-to-wheel perspective and consider all involved processes.

\section{Problem description and formulation}

The concerned problem is the design of a biodiesel supply chain network integrating all involved stages from feedstock supply centers to distribution of biodiesel and by-product glycerin under uncertainty. The problem is of a multi-product, multi-period, multi-modal, and capacitated supply chain network design problem. As illustrated in Fig. 1, JCL seeds are harvested from farms and UCO is collected from different cities and then shipped to JCL oil extraction and UCO collection centers, respectively. JCL oil is extracted from received seeds by cold pressing technology [43] and UCO is purified in UCO collection centers by suitable filtration. Then, the extracted and purified oils are shipped to bio-refinery centers and converted to main product biodiesel and by-product glycerin using transesterification process [44]. Biodiesel is shipped to end customers through distribution centers, but glycerin is directly transported to related customers. All the facilities considered in this biodiesel network are linked via two transportation modes: road and rail. Road route is available between all potential locations considered for establishing facilities, but rail route is limited between some locations.

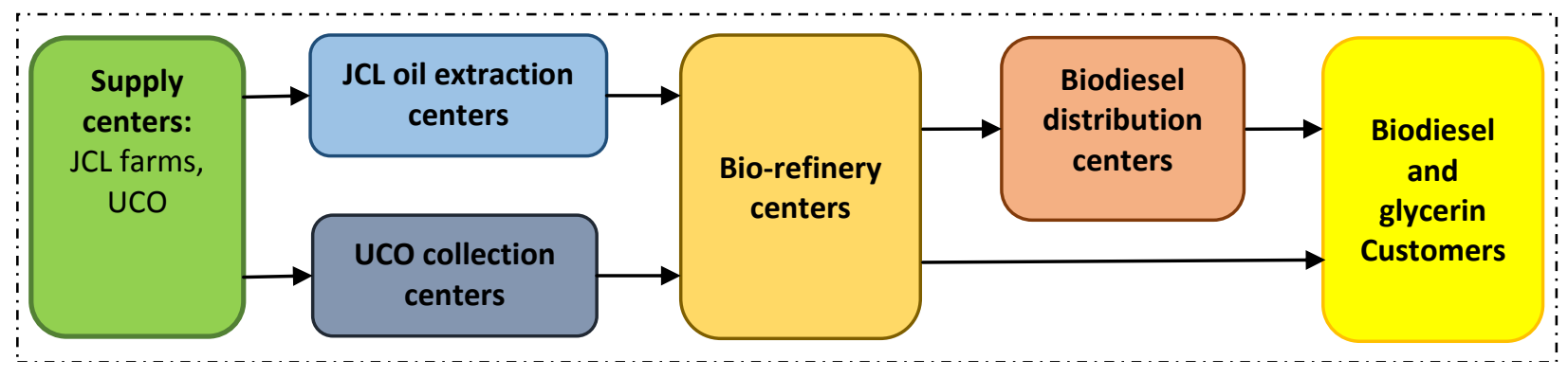

Fig. 1. Illustration of the integrated Biodiesel supply chain network and environmental impact

The concerned feedstocks are non-edible feedstocks which do not compete with food crops and are only used for biodiesel production. In the considered integrated biodiesel supply chain network only the locations of UCO supply centers and final customers are priori known, but 
other locations of facilities in each layer should be selected from the candidate locations. The problem is considered for 21-year planning horizon. However, to reduce computational complexity of the problem, each three years is considered as a time period. Therefore, the overall planning horizon is divided into seven periods. Inventory holding throughout the biodiesel supply chain from feedstock centers to consumers is considered to adequately match feedstock supply and biodiesel demand [45]. We assume that JCL feedstock is cultivated in arid and semiarid areas of each city and other fertile lands are used for food crops cultivation. It is assumed that cultivation cost of JCL is dependent upon the amount of cultivated area and varies based on a piecewise linear function form. Also, the main important input parameters of the model are really uncertain. To represent their uncertainty possibilistic distribution is constructed by the aid of some historical data and expert's opinions. The minimization of total involved costs and the total EI of processes are considered as OFs.

The main decisions which should be addressed by the proposed MO-PBSCND model under above-mentioned assumptions are as follows:

(1) Strategic decision variables which include optimum numbers, locations and capacities of JCL cultivation centers, oil extraction centers of JCL seeds, collection centers of UCO, bio-refineries, and distribution centers. The capacities of established facilities are continuous decision variables and hence their exact values are determined by the proposed model. This type of formulation for capacity determination is computationally better than the approaches that consider discrete levels for capacity of facilities (see [46]). This assumption is as the same as assumption of Andersen et al. [2]. Notably capacity may be expanded by changing the current installed devices e.g. pumps, pipes, and furnace or by installing new production line at the established facility. (2) Tactical decision variables which include the amounts of production, inventory levels, imported JCL, aggregate material flow between network nodes, and suitable transportation modes in different periods. Our motivation for such integration is to avoid sub-optimal solutions resulted due to separated decision making for tactical and strategic level decisions [47].

\subsection{Environmental impact}

To move toward sustainable design of biodiesel SCs, EI of the all involved processes in the considered SC from upstream to downstream section should be assessed under a well-to-wheel perspective [32]. In this paper, EI of the considered biodiesel network is assessed by Eco- 
indicator 99 method employing SimaPro software. The calculation procedure of EI of different processes involved in the considered biodiesel SC is described in Section 6.

\subsection{Model formulation}

The indices, parameters and variables used to formulate the concerned MO-PBSCND problem are described in Appendix A. Notably, Parameters with tilde on indicate coefficients tainted with possibilistic uncertainty.

\section{Cost objective function}

Cost objective function of the proposed MO-PBSCND model minimizes total costs including:

Fixed opening costs:

$\sum_{f} \sum_{t} F \tilde{C} J_{f t} x_{f}+\sum_{i} \sum_{t} F \tilde{C} C_{i t} u_{i}+\sum_{s} \sum_{t} F \tilde{C} W_{s t} y_{s}+\sum_{j} \sum_{t} F \tilde{C} B_{j t} \nu_{j}+\sum_{k} \sum_{t} F \tilde{C} S_{k t} w_{k}$

Variable opening costs:

$\sum_{f} V \tilde{C} J_{f}\left(C J_{f}\right) \cdot C J_{f}+\sum_{i} \sum_{t} V \tilde{C} C_{i t} C C_{i t}+\sum_{s} \sum_{t} V \tilde{C} W_{s t} C W_{s t}+\sum_{j} \sum_{t} V \tilde{C} B_{j t} C B_{j t}+\sum_{k} \sum_{t} V \tilde{C} S_{k t} C S_{k t}$

In the above equation, the amount of variable cost of JCL cultivation is dependent upon the area to be cultivated (i.e. $C J_{f}$ ) and thus is a non-linear equation. Variation of variable cultivation cost in terms of the amount of cultivated area is a piecewise linear function illustrated in Fig. 2.

Production costs:

$\sum_{f} \sum_{t} P \tilde{C} J_{f t} P J_{f t}+\sum_{g} \sum_{t} P \tilde{C} C_{g t} W O_{g t}+\sum_{i} \sum_{t} P \tilde{C} O_{i t} P O_{i t}+\sum_{s} \sum_{t} P \tilde{C} W_{s t} P W_{s t}$

$+\sum_{j} \sum_{t} P \tilde{C} B_{j t} P B_{j t}+\sum_{j} \sum_{t} P \tilde{C} G_{j t} P G_{j t}$

Inventory holding costs:

$\sum_{i} \sum_{t} I \tilde{C} J_{i t} I J_{i t}+\sum_{s} \sum_{t} I \tilde{C} W_{s t} I W_{s t}+\sum_{j} \sum_{t} I \tilde{C} B_{j t} I B_{j t}+\sum_{j} \sum_{t} I \tilde{C} G_{j t} I G_{j t}+\sum_{k} \sum_{t} I \tilde{C} S_{k t} I S_{k t}$

Transportation costs: 
$\sum_{f} \sum_{l} \sum_{i} \sum_{t} J \tilde{C} T_{f l i t} J T_{f l i t}+\sum_{g} \sum_{l} \sum_{s} \sum_{t} W \tilde{C} T_{g l s t} W T_{g l s t}+\sum_{i} \sum_{l} \sum_{j} \sum_{t} O \tilde{C} T_{i l j t} O T_{i l j t}$

$+\sum_{s} \sum_{l} \sum_{j} \sum_{t} V \tilde{C} T_{s j i t} V T_{s l j t}+\sum_{j} \sum_{l} \sum_{k} \sum_{t} B \tilde{C} T_{j l k t} B T_{j k t}+\sum_{k} \sum_{l} \sum_{c} \sum_{t} M \tilde{C} T_{k l c t} M T_{k l c t}$

$+\sum_{j} \sum_{l} \sum_{n} \sum_{t} G \tilde{C} T_{j l n t} G T_{j l h t}$

Importing costs:

$\sum_{i} \sum_{t} C \tilde{I m}_{i t} I m_{i t}$

Finally, Cost objective function is equal to summation of terms (1) to (6). The NPV of the cost objective function is calculated by multiplying the cost objective function by discount factor $\frac{3+3 \xi+\xi^{2}}{3(1+\xi)^{2 t}}$ [32], where $\xi$ is interest rate and assumed to be constant over different periods. In this paper discount factor is assumed to be $\% 10$. Note that the used discount factor is valid for a period of 3 years.

\section{Environmental objective function}

Environmental OF of the proposed MO-PBSCND model minimizes total environmental impact including:

Environmental impact of establishing facilities and related capacity installation:

$\sum_{f} \tilde{e} x_{f} x_{f} C J_{f}+\sum_{i} \sum_{t} \tilde{e} u_{i} u_{i} C C_{i t}+\sum_{s} \sum_{t} \tilde{e} y_{s} y_{s} C W_{s t}+\sum_{j} \sum_{t} \tilde{e v}{ }_{j} v_{j} C B_{j t}+\sum_{k} \sum_{t} \tilde{e} w_{k} w_{k} C S_{k t}$

In equation (7) multiplying establishing binary and continuous capacity installation variables imposes non-linearity to the environmental OF.

Environmental impact of production process at different facilities:

$\sum_{g} \sum_{t} \tilde{E} C_{g} W O_{g t}+\sum_{i} \sum_{t} \tilde{E} O_{i} P O_{i t}+\sum_{s} \sum_{t} \tilde{E} W_{s} P W_{s t}+\sum_{j} \sum_{t} \tilde{E} B_{j} P B_{j t}+\sum_{j} \sum_{t} \tilde{E} G_{j} P G_{j t}$

Environmental impact of Inventory holding:

$\sum_{i} \sum_{t} E \tilde{I I}_{i} I J_{i t}+\sum_{s} \sum_{t} E \tilde{I} \tilde{W}_{s} I W_{s t}+\sum_{j} \sum_{t} E \tilde{I B}_{j} I B_{j t}+\sum_{j} \sum_{t} E \tilde{I} \tilde{G}_{j} I G_{j t}+\sum_{k} \sum_{t} E \tilde{I} \tilde{S}_{k} I S_{k t}$

Environmental impact of transporting material between different nodes in the network: 
$\sum_{f} \sum_{l} \sum_{i} \sum_{t} E \tilde{J T}_{f l i} D i s J T_{f l i} J T_{f l i t}+\sum_{g} \sum_{l} \sum_{s} \sum_{t} E W T_{g l s} D i s W T_{g l s} W T_{g l s t}$

$+\sum_{i} \sum_{l} \sum_{j} \sum_{t} E \tilde{O T} T_{i l j} D i s O T_{i l j} O T_{i l j t}+\sum_{s} \sum_{l} \sum_{j} \sum_{t} E \tilde{V T} T_{s l j} D i s V T_{s l j} V T_{s j t}$

$+\sum_{j} \sum_{l} \sum_{k} \sum_{t} E \tilde{B} T_{j l k} D i s B T_{j l k} B T_{j l k t}+\sum_{k} \sum_{l} \sum_{c} \sum_{t} E \tilde{M} T_{k l m} D i s M T_{k l c} M T_{k l c t}$

$+\sum_{j} \sum_{l} \sum_{n} \sum_{t} E \tilde{G} T_{j l n} D i s G T_{j l n} G T_{j l n t}$

Environmental impact of importing JCL seeds:

$\sum_{i} \sum_{t} E \tilde{I m}_{i t} \operatorname{Im}_{i t}$

Consequently, environmental OF is equal to summation of terms (7) to (11).

The aim of the proposed MO-PBSCND model is to simultaneously minimize the total costs and environmental impact of designing biodiesel supply chain network under uncertainty subject to the following constraints:

$\sum_{k} \sum_{l} M T_{k l c t} \geq \tilde{D}_{c t} \quad \forall c, t$

$\sum_{j} \sum_{l} G T_{j h t} \geq \tilde{D} E_{n t} \quad \forall n, t$

$\sum_{l} \sum_{s} W T_{g l s t}=\tilde{W} O_{g t} \quad \forall g, t$

$\sum_{l} \sum_{i} J T_{f l i t}=P J_{f t} \quad \forall f, t$

$P J_{f t}=\tilde{\eta}_{f t} C J_{f} \quad \forall f, t$

$P O_{i t}=\varphi \sum_{f} \sum_{l} J T_{\text {flit }} \quad \forall i, t$

$P W_{s t}=\beta \sum_{g} \sum_{l} W T_{g l s t} \quad \forall s, t$

$P B_{j t}=\pi \sum_{i} \sum_{l} O T_{i l j t}+\omega \sum_{s} \sum_{l} V T_{s l j t} \quad \forall j, t$

$P G_{j t}=(1-\pi) \sum_{i} \sum_{l} O T_{i j j t}+(1-\omega) \sum_{s} \sum_{l} V T_{s l j t} \quad \forall j, t$

$I J_{i t}=I J_{i, t-1}+I m_{i t}+\sum_{f} \sum_{l} J T_{f l i t}-\left(\frac{1}{\alpha}\right) \sum_{l} \sum_{j} O T_{i l j t} \quad \forall i, t$ 


$$
\begin{aligned}
& I W_{s t}=I W_{s, t-1}+\sum_{g} \sum_{l} W T_{g l s t}-\left(\frac{1}{\beta}\right) \sum_{l} \sum_{j} V T_{s l j t} \quad \forall s, t \\
& I B_{j t}=I B_{j, t-1}+P B_{j t}-\sum_{l} \sum_{k} B T_{j k t} \quad \forall j, t \\
& I G_{j t}=I G_{j, t-1}+P G_{j t}-\sum_{l} \sum_{n} G T_{j h t} \quad \forall j, t \\
& I S_{k t}=I S_{k, t-1}+\sum_{j} \sum_{l} B T_{j k t}-\sum_{l} \sum_{c} M T_{k l c t} \quad \forall k, t \\
& x_{f} L A_{f} \leq C J_{f} \leq x_{f} U A_{f} \quad \forall f \\
& C C_{i t}=C C_{i, t-1}+C E C_{i t} \quad \forall i, t \\
& u_{i} L C_{i} \leq C C_{i t} \leq u_{i} U C_{i} \quad \forall i, t \\
& C W_{s t}=C W_{s, t-1}+C E W_{s t} \quad \forall s, t \\
& y_{s} L W_{s} \leq C W_{s t} \leq y_{s} U W_{s} \quad \forall s, t \\
& C B_{j t}=C B_{j, t-1}+C E B_{j t} \quad \forall j, t \\
& v_{j} L B_{j} \leq C B_{j t} \leq v_{j} U B_{j} \quad \forall j, t \\
& C S_{k t}=C S_{k, t-1}+C E S_{k t} \quad \forall k, t \\
& w_{k} L S_{k} \leq C S_{k t} \leq w_{k} U S_{k} \quad \forall k, t \\
& \sum_{f} x_{f} \leq \operatorname{Maxx} \\
& \sum_{s} y_{s} \leq \operatorname{Maxy} \\
& \sum_{i} u_{i} \leq \operatorname{Maxu} \\
& \sum_{j} v_{j} \leq \operatorname{Max} v \\
& \sum_{k} w_{k} \leq \operatorname{Maxw} \\
& \operatorname{Im}_{i t} \leq \operatorname{MaxIm}_{i t} \\
& \sum_{f} \sum_{l} J T_{f l i t}+I m_{i t} \leq C C_{i t} \quad \forall i, t
\end{aligned}
$$


$\sum_{i} \sum_{l} O T_{i l j t}+\sum_{s} \sum_{l} V T_{s j i t} \leq C B_{j t} \quad \forall j, t$

$\sum_{g} \sum_{l} W T_{g l s t} \leq C W_{s t} \quad \forall s, t$

$\sum_{j} \sum_{l} B T_{j l k t} \leq C S_{k t} \quad \forall k, t$

$x_{f}, y_{s}, u_{i}, v_{j}, w_{k} \in\{0,1\} \quad \forall f, s, i, j, k$

All Continuous decision variables $\geq 0$

Constraints (12) and (13) satisfy biodiesel and glycerin demands at different cities for each period, respectively. Equations (14) and (15) ensure that all JCL seeds and UCO are collected and transported to oil extraction and collection centers in each period, respectively. Equation (16) shows that the amount of JCL seeds produced in each cultivated area in any period. Equations (17) and (18) illustrate the amount of JCL oil production and purified UCO at related facilities in each period. Equations (19) and (20) state the amount of biodiesel and glycerin production at a bio-refinery in each period from JCL oil and UCO received from corresponding facilities. It is worthy to note that biodiesel and glycerin are produced according to the following transesterification process in bio-refineries [44].

Oil + Methanol $\longrightarrow$ Biodiesel + Glycerin + Methanol

Methanol is commonly used as a catalyzer in transesterification process due to its low cost [48]. Since the amount of produced methanol by transesterification is low and is recovered, we ignore the amount of produced methanol. Indeed, we assume that the JCL or UCO oil is only transformed to biodiesel and glycerin.

Equation (21) is inventory balance constraint at an oil extraction center of JCL seeds. This constraint ensures that the inventory of JCL seeds at any oil extraction center in any period is equal to the summation of inventory of JCL seeds left from previous period, the amount of JCL seeds imported from foreign countries, the amount of JCL yields produced in that period, minus the amount of JCL seeds transformed to oil and shipped to bio-refineries. Constraints (22) to (25) are inventory balance equations for UCO, biodiesel and glycerin at related facilities.

Constraint (26) binds lower and upper bound for selected locations for JCL cultivation. Lower bound is considered due to economy of scale consideration and upper bound is considered because of biodiversity concern. Regarding the fact that JCL yields after two years of cultivation 
and in order to keep continuous yielding of JCL trees, we assume that capacity of JCL cultivation area is not dependent on time period. On the other hand, capacity of other facilities is dependent on time periods to be expanded according to increase of biodiesel demands and required feedstock for fulfilling demands. In this regard, constraints (27) and (28) take into account capacity expansion and lower and upper bound for established oil extraction centers of JCL seeds. Capacity of any established facility in each period is equal to capacity determined in prior period and capacity expanded in current period. Constraints (29) to (34) are capacity expansions and lower and upper bounds in collection centers of UCO, bio-refineries, and distribution centers, respectively. Note that when a facility is determined (i.e., corresponding binary variable is 1), its corresponding capacity will be between defined lower and upper bound. On the other hand, when binary variable of a specific facility is zero, its related capacity will be zero.

Constraints (35) to (39) consider upper bound on the number of different facilities could be opened. These constraints are implied due to budget limitations for establishing different facilities. Constraint (40) consider upper bound on the amount of JCL seeds could be imported in different periods. This constraint is considered because of reducing dependency on foreign suppliers and therefore reduction of disruption risks [49].

Constraints (41) to (44) are capacity constraints at oil extraction centers of JCL seeds, collection centers of UCO, bio-refineries, and distribution centers, respectively. Finally, constraints (45) and (46) enforce binary and non-negativity restrictions on the related decision variables.

\subsection{Linearization of the non-linear terms in the considered objective functions}

As previously mentioned, non-linear terms in equations (2) and (7) lead to non-linearity of the cost and environmental OFs. Although the non-linear mathematical programming models reflect the real and practical assumptions, finding global solutions for non-linear problems is computationally difficult and unachievable in some cases. In this paper, we employ appropriate linearization techniques to escape difficulty of solving the proposed non-linear MO-PBSCND model.

In most industries increasing the amount of production leads to decreasing rate of production costs because of economy of scale principle [50]. This issue is highlighted in agriculture subject such that variable cultivation cost is significantly dependent on the quantity of cultivated area. In 
this paper, without loss of generality, we assume that cultivation cost is dependent on the amount of cultivated area and varies according Fig. 2.

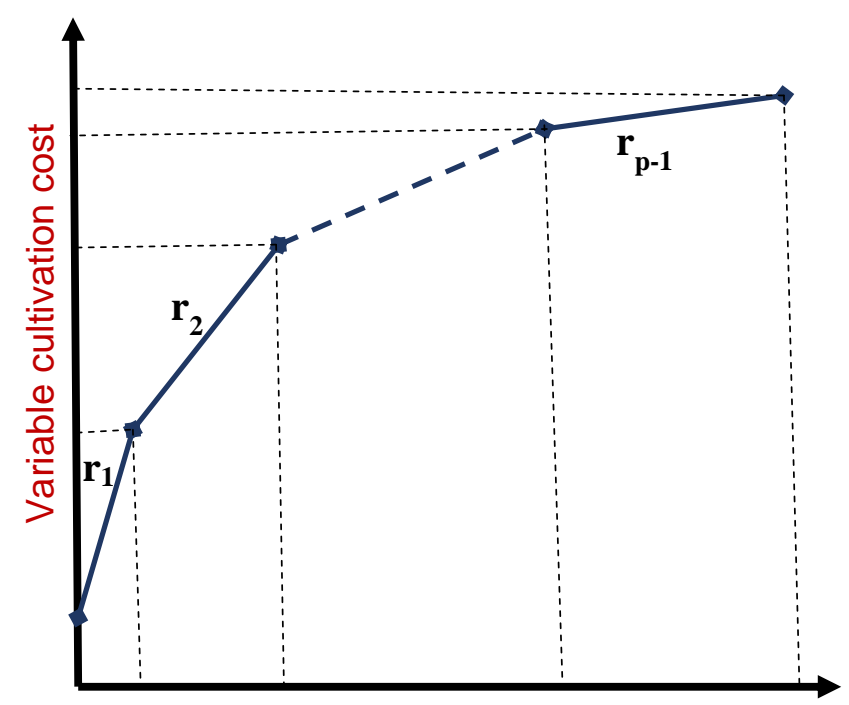

Quantity of cultivated area (ha)

Fig. 2. Piecewise linear function of variable cultivation cost

This piecewise linear form leads to non-linearity of the considered cost OF. Equations (47) model the behavior of piecewise linear function illustrated in Fig. 2.

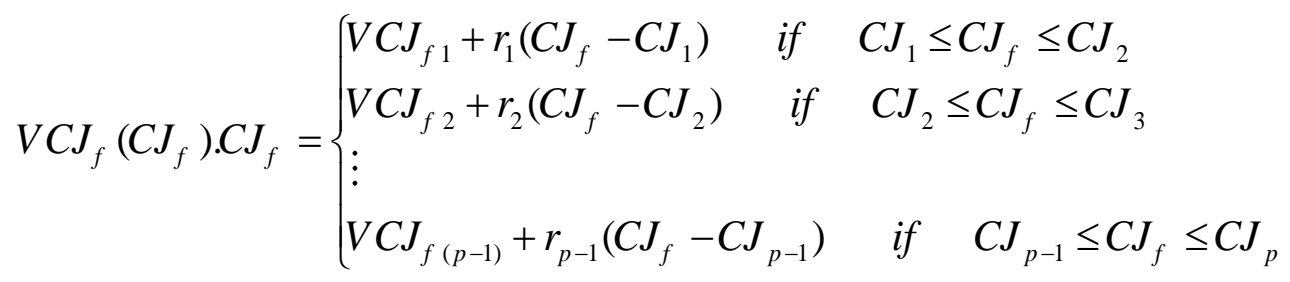

Where $r_{i}$ is the slope when the JCL cultivated area is between $C J_{i}$ and $C J_{i+1}$, and $p$ represents that piecewise linear function of cultivation cost is divided into p-1 line segments. In equation (47) variable cultivation cost (i.e. $V C J_{f}$ ) is a function of the amount of cultivated area (i.e. $C J_{f}$ ). The main problem in using equation (47) for calculating variable cultivation cost is that the optimal amount of cultivated area is priori unknown and therefore using appropriate equation from Equations (47) for taking into account the variable cultivation cost is conditional.

$\mathrm{Li}$ and $\mathrm{Yu}$ [51] proposed a linearization technique to convert the piecewise linear function to a linear form. In this way, firstly the piecewise linear function is converted to an equivalent mathematical programming model. Then, since the equivalent model has a nonlinear squared function, it is approximated by multiple breakpoints (see [50]). It is evident that approximation 
of a non-linear squared function reduces the accuracy of the results and may be lead to misleading results in large real cases. To eliminate drawback of this method, we use special ordered set of type 2 (SOS2) proposed in [52]. Special ordered sets are efficient tools used in modeling non-convex functions and many discrete optimization problems and are divided into two types 1 and $2[53,54]$. SOS1 is defined as a set of variables in which at most one of the variables in the set can be nonzero and all other being at zero [55]. SOS2 is defined as a set of variables of which at most two variables may be nonzero and if two variables are nonzero, they must be consecutive in the set. In Equation (47), since the optimal quantity of cultivated area will occur between two consecutive $C J_{i}$ and $C J_{i+1}$, we must use SOS2. The linearization procedure by using SOS2 tool is as follows:

Variable $C J_{f}$ is restricted to lie between $C J_{1}$ and $C J_{p}$ and therefore can be modeled via convex combination of two consecutive points existing in set of endpoints $\left\{C J_{l}, C J_{2}, \ldots, C J_{p}\right\}$. Equations (48) to (50) represent convex combination of $C J_{f}$ by all points existing in set $\left\{C J_{l}\right.$, $\left.C J_{2}, \ldots, C J_{p}\right\}$.

$$
\begin{aligned}
& C J_{f}=\lambda_{f 1} C J_{1}+\lambda_{f 2} C J_{2}+\ldots+\lambda_{f p} C J_{p}=\sum_{i=1}^{p} \lambda_{f i} C J_{i} \\
& \sum_{i=1}^{p} \lambda_{f i}=1 \quad \forall f=1, \ldots, F \\
& \lambda_{f i} \geq 0 \quad \forall i=1, \ldots, p ; f=1, \ldots, F
\end{aligned}
$$

Where $\lambda_{f i}$ are non-negative continuous variables used to construct convex combination. In order to select two consecutive $C J_{i}$ and $C J_{i+1}$ from Equation (48) and calculating continuous amount of $C J_{f}$, we should add SOS2 Constraints (51).

$$
\lambda_{f 1}, \lambda_{f 2}, \lambda_{f 3}, \ldots, \lambda_{f p} \in \operatorname{SoS} 2
$$

Constraints (51) are defined by Constraints (52) to (58):

$$
\begin{aligned}
& \lambda_{f 1} \leq \delta_{f 1} \\
& \lambda_{f 2} \leq \delta_{f 1}+\delta_{f 2} \\
& \lambda_{f 3} \leq \delta_{f 2}+\delta_{f 3}
\end{aligned}
$$


$\lambda_{f(p-1)} \leq \delta_{f(p-2)}+\delta_{f(p-1)}$

$\lambda_{f p} \leq \delta_{f(p-1)}$

$\delta_{f i} \in\{0,1\} \quad \forall i=1, \ldots,(p-1) ; f=1, \ldots, F$

$\sum_{i=1}^{p-1} \delta_{f i}=1 \quad \forall f=1, \ldots, F$

It is straightforward that SOS2 constraints select two adjacent endpoints from Equation (58). Finally, considering the optimal values of two consecutive $\lambda_{f i}$ and $\lambda_{f(i+1)}$, the total variable cultivation cost is calculated by Equation (59) in the cost OF. Really, Equation (59) is a convex combination of endpoints of variable cultivation cost.

$V C J_{f}\left(C J_{f}\right) \cdot C J_{f}=\sum_{i=1}^{p} \lambda_{f i} V C J_{f i}\left(C J_{i}\right)$

It is clear that Equation (59) is an equivalent linear form of non-linear Equation (47) and hence takes into account the accurate value of total variable cultivation cost.

Other nonlinear form of the proposed MO-PBSCND model is related to multiplying two binary and continuous decision variables in Equation (7) of environmental OF. The nonlinear terms in Equation (7) can be conveniently converted to linear form by introducing additional continuous variable [56]. For example, in the first term of Equation (7) additional continuous variable $C J x_{f}$ is replaced by multiplied binary and continuous variables (i.e., $C J x_{f}=x_{f} C J_{f}$ ) and then the related bounds are implied. Equations (60) to (62) represent the linearization of the first term in Equation (7).

$C J x_{f}=x_{f} C J_{f}$

$0 \leq C J x_{f} \leq C J_{f}$

$C J_{f}-\operatorname{BigM}_{f}\left(1-x_{f}\right) \leq C J x_{f} \leq \operatorname{BigM}_{f} x_{f}$

Where $B i g M_{f}$ is a big number. If $x_{f}=0$, then right-hand side of inequality (62) equals to zero and the left-hand side would be an enormous negative number. Considering constraint (61), we have $C J x_{f}=0$. On the other hand, if $x_{f}=1$, then inequality (62) operates as $C J_{f}$, contradiction between this result and constraint (61) contains $C J_{f}=C J_{f}$. Other nonlinear terms are converted to their equivalent linear forms through Constraints (63) to (74).

$$
\begin{aligned}
& C C u_{i t}=u_{i} C C_{i t} \\
& 0 \leq C C u_{i t} \leq C C_{i t}
\end{aligned}
$$




$$
\begin{aligned}
& C C_{i t}-\operatorname{Big}_{i t}\left(1-u_{i}\right) \leq C C u_{i t} \leq \operatorname{Big}_{i t} u_{i} \\
& C W y_{s t}=y_{s} C W_{s t} \\
& 0 \leq C W y_{s t} \leq C W_{s t} \\
& C W_{s t}-B i g M_{s t}\left(1-y_{s}\right) \leq C W y_{s t} \leq B i g M_{s t} \cdot y_{s} \\
& C B v_{j t}=v_{j} C B_{j t} \\
& 0 \leq C B v_{j t} \leq C B_{j t} \\
& C B_{j t}-B i g M_{j t}\left(1-v_{j}\right) \leq C B v_{j t} \leq B i g M_{j t} \cdot v_{j} \\
& C S w_{k t}=w_{k} C S_{k t} \\
& 0 \leq C S w_{k t} \leq C S_{k t} \\
& C S_{k t}-B i g M_{k t}\left(1-w_{k}\right) \leq C S w_{k t} \leq B i g M_{k t} \cdot w_{k}
\end{aligned}
$$

The important point about the amount of BigM in different Equations (65) to (74) is that its value has great impact in reducing computational efforts of solving procedure such that setting very large value for $B i g M$ will increase computational time [54]. Therefore its amount is case-specific and should be determined according to the structure of input data in the studied problem. In our case, since capacity variables lie between defined lower and upper bounds, we can set BigM values slightly more than defined upper bounds for capacities of different facilities.

\section{Proposed possibilistic mean-absolute deviation model}

As mentioned in previous section, the main parameters of the proposed model have been tainted with uncertainty. In our case, due to lack of enough historical data making probabilistic distribution for uncertain parameters is not possible, instead limited historical data and expert's opinions can be efficiently used to construct possibility distribution of uncertain parameters [57]. One of the main disadvantage of different available possibilistic programming method either based on expected value [58] or mean value [59] is that they only consider expected or mean values of $\mathrm{OF}$ in developing possibilistic-based solution methods. However, risk control of OF has been neglected in these models and all decisions are made under average condition of uncertain parameters realization. But, in real world applications managers prefer to involve risk of investment in decision making process. Also, inefficiency of risk-neutral approaches is highlighted in design and planning problems such as the considered biodiesel supply chain 
network design problem [60]. Risk issue has been widely studied in stochastic environments in different areas [61], but its investigating under epistemic and fuzzy conditions is scarce [62]. According to [61], "Supply chain risk is the potential loss for a supply chain in terms of its target values of efficiency and effectiveness evoked by uncertain developments of supply chain characteristics whose changes were caused by the occurrence of triggering-events".

Additionally, according to the classification of [63] about supply chain risks, this study models the following risks of SC: material flow risk (feedstock supply), deliver (demand volatility/seasonality), financial flow (variation of different investment, production, and transportation costs), and Environmental impact (variation of EI coefficients). Also, other supply chain risks such as information flow, natural disasters, operational disruption, political, product design and supplier selection are not addressed in this paper.

In this paper, we propose a new formulation of possibilistic programming approach integrating mean and absolute deviation of the uncertain OF. Possibilistic absolute deviation of uncertain OF is considered as a risk measure in this formulation. The proposed new formulation is an extension of formulation proposed in [62]. In formulation of Zhang and Zhang [62] absolute deviation is considered as a constraint and its upper bound is defined through decision maker (DM) preferences. Indeed, in their formulation risk of possibilistic OF is not optimized. In our formulation, we integrate risk factor in OF to be optimized beside mean value of possibilistic OF. Another difference is that they apply their method in a multi-period portfolio selection problem. Triangular and trapezoidal fuzzy numbers are the most popular and practical fuzzy numbers used for modeling fuzzy parameters. According to the structure of the uncertain parameters in the studied case and expert's opinion, we use triangular fuzzy number to model data uncertainty.

In Appendix B, some definitions required in developing the proposed possibilistic mean-absolute deviation model are presented for interested readers.

At the following, the novel formulation of possibilistic mathematical programming model is presented with ambiguous coefficient in both OFs and constraints. The proposed model is based on mean and absolute deviation of fuzzy numbers. Also, the procedure to convert the proposed possibilistic model to its equivalent crisp model has been stated in Appendix B.

The possibilistic mean-absolute deviation model is as follows: 


$$
\begin{array}{ll}
\text { Min } & z=\bar{M}(\tilde{c} x)+\gamma|\sigma(\tilde{c x})| \\
\text { s.t. } & \tilde{a}_{i} x \geq \tilde{b_{i}}, \quad i=1, \ldots, l \\
& \tilde{a}_{i} x=\tilde{b_{i}}, \quad i=l+1, \ldots, m \\
& x \geq 0
\end{array}
$$

In the above model, the first term in OF minimizes the possibilistic mean value of $\tilde{c} x$ while the second term minimizes the possibilistic absolute deviation of $\tilde{c} x$. Using the $\gamma$ (risk coefficient), the trade-off between possibilistic mean value and absolute deviation of OF can be determined through the multiple-criteria decision making (MCDM) techniques. The proposed possibilistic programming model is similar to the robust stochastic programming model proposed in [64] except that our approach has been proposed for fuzzy environments. Also, the proposed formulation of the possibilistic programming method can be categorized within realistic robust possibilistic programming approaches (see [57]). Really, minimizing pure expected values [58] or mean values [62] of $\mathrm{OF}$ in a possibilistic mathematical programming model does not guarantee to achieve robust solutions. In other words, these models are risk-neutral. The proposed model allows the DMs to consider risk-averse aspects in decision making besides considering the average condition under uncertainty. It should be noted that other measures such as variance of fuzzy numbers proposed in [59] can be used as risk measure in possibilistic OF of problem (75). However, using variance measure results non-linear possibilistic programming model and thus increases solving challenges of the problem. In the following, the equivalent crisp model of the proposed possibilistic mean-absolute deviation model is presented. According to the definitions and principles presented in Appendix B, the equivalent crisp model of the proposed possibilistic mean-absolute deviation model (75) is stated as follows:

$\operatorname{Min} Z=\left(\frac{c^{p}+4 c^{m}+c^{o}}{6}\right) x+\gamma\left(\frac{c^{o}-c^{p}}{3}\right) x$

s.t.

$$
\begin{aligned}
& {\left[(1-\alpha)\left(\frac{2}{3} a^{m}+\frac{1}{3} a^{o}\right)+\alpha\left(\frac{2}{3} a^{m}+\frac{1}{3} a^{p}\right)\right] x \geq \alpha\left(\frac{2}{3} b^{m}+\frac{1}{3} b^{o}\right)+(1-\alpha)\left(\frac{2}{3} b^{m}+\frac{1}{3} b^{p}\right), i=1, \ldots, l} \\
& {\left[\left(1-\frac{\alpha}{2}\right)\left(\frac{2}{3} a^{m}+\frac{1}{3} a^{o}\right)+\frac{\alpha}{2}\left(\frac{2}{3} a^{m}+\frac{1}{3} a^{p}\right)\right] x \geq \frac{\alpha}{2}\left(\frac{2}{3} b^{m}+\frac{1}{3} b^{o}\right)+\left(1-\frac{\alpha}{2}\right)\left(\frac{2}{3} b^{m}+\frac{1}{3} b^{p}\right), i=l+1, \ldots, m} \\
& {\left[\frac{\alpha}{2}\left(\frac{2}{3} a^{m}+\frac{1}{3} a^{o}\right)+\left(1-\frac{\alpha}{2}\right)\left(\frac{2}{3} a^{m}+\frac{1}{3} a^{p}\right)\right] x \leq\left(1-\frac{\alpha}{2}\right)\left(\frac{2}{3} b^{m}+\frac{1}{3} b^{o}\right)+\frac{\alpha}{2}\left(\frac{2}{3} b^{m}+\frac{1}{3} b^{p}\right), i=l+1, \ldots, m} \\
& \quad x \geq 0
\end{aligned}
$$


Therefore, according to problem (76) the possibilistic OFs and constraints (12) to (14) and (16) of the proposed MO-PBSCND model can be conveniently converted to their equivalent crisp model. Due to space limitation, the equivalent crisp model of the proposed MO-PBSCND model is not presented here.

\section{The proposed solution approach}

In multi-objective problems (MOPs), efficient or Pareto-optimal solutions are explored instead of optimal solutions. Solution approaches for MOPs are categorized into three groups: priori, interactive and posteriori approaches [65]. In priori methods, the DM should determine the goals or weights to objectives before the solution process which, in turn, is a difficult and complex task [66]. In interactive methods, most preferred solutions are progressively and interactively explored according to DM preferences [67]. The main drawback of this method is that only preferred solutions of DM are found and other efficient solutions which may be interesting for DM are omitted. In posteriori methods, some efficient solutions of Pareto-optimal curve are determined and if the DM is not satisfied with acquired solutions, more efficient solutions are explored. Although posteriori methods are computationally less interesting than other methods, these methods provide efficient solutions from the whole Pareto-optimal set for the DM. Three mentioned approaches have been widely applied in MOPs, but the main concern in developing these methods is that the applied method should be capable to explore only efficient solutions rather than weakly efficient solutions [68].

The $\varepsilon$-constraint method is one of the most popular posteriori methods in which the Paretooptimal set is achieved through changing the $\varepsilon$-vectors of objectives considered as constraints and solving their corresponding single objective problems [69]. Two main drawbacks of $\varepsilon$ constraint method are: (1) the optimal range of OFs is not determined over the efficient set, and (2) the method may lead to generating inefficient solutions [66]. Mavrotas [66] presented an augmented $\varepsilon$-constraint method generating only efficient solutions.

Here, we propose two-phased approach for solving the proposed MO-PBSCND problem. In the first phase, the possibilistic-based OFs and constraints are converted to their equivalent crisp forms by the principles described in Section 4. In the second phase, a hybrid flexible lexicographic and augmented $\varepsilon$-constraint method is applied to provide universe image from the 
Pareto-optimal set. The main difference between our approach for solving MOPs and [66] is that we consider flexible lexicographic method to optimize the range of OFs and construct the payoff table according to DM preferences about satisfaction degree of violation of each OF from its optimal value.

Without loss of generality, consider $p$ OFs of the MOP which should be minimized. The $\varepsilon$ constraint method optimizes the main OF (for example, $f_{l}$ ) subject to the feasibility constraints and constrained objectives and is stated as follows [69]:

$\operatorname{Min}\left\{f_{1}(x) \mid x \in X \wedge f_{i}(x) \leq \varepsilon_{i}, \quad i=2, \ldots, p\right\}$

Where $x$ is the vector of decision variables and $X$ represents the feasible decision space. The problem (77) is a single objective problem and can be conveniently solved for different $\varepsilon$-vectors and the DM can select the most preferred solution among the efficient set. To generate different $\varepsilon$-vectors, first pay-off table with $p$ rows and columns is constructed through optimizing the range of OFs over the efficient set. The diagonal of pay-off table indicates the optimal value of each OF. Then, the ranges of constrained $p-1$ objectives are divided into a number of intervals based on some grid points. In this way, the positive ideal solution $\left(f^{P I S}\right)$ and negative ideal solution $\left(f^{N I S}\right)$ for each objective is provided by the pay-off table being the ranges of each objective [68]. In this paper, to obtain the $f^{P I S}$ and $f^{N I S}$ for each objective, flexible lexicographic method is used according to algorithm 1.

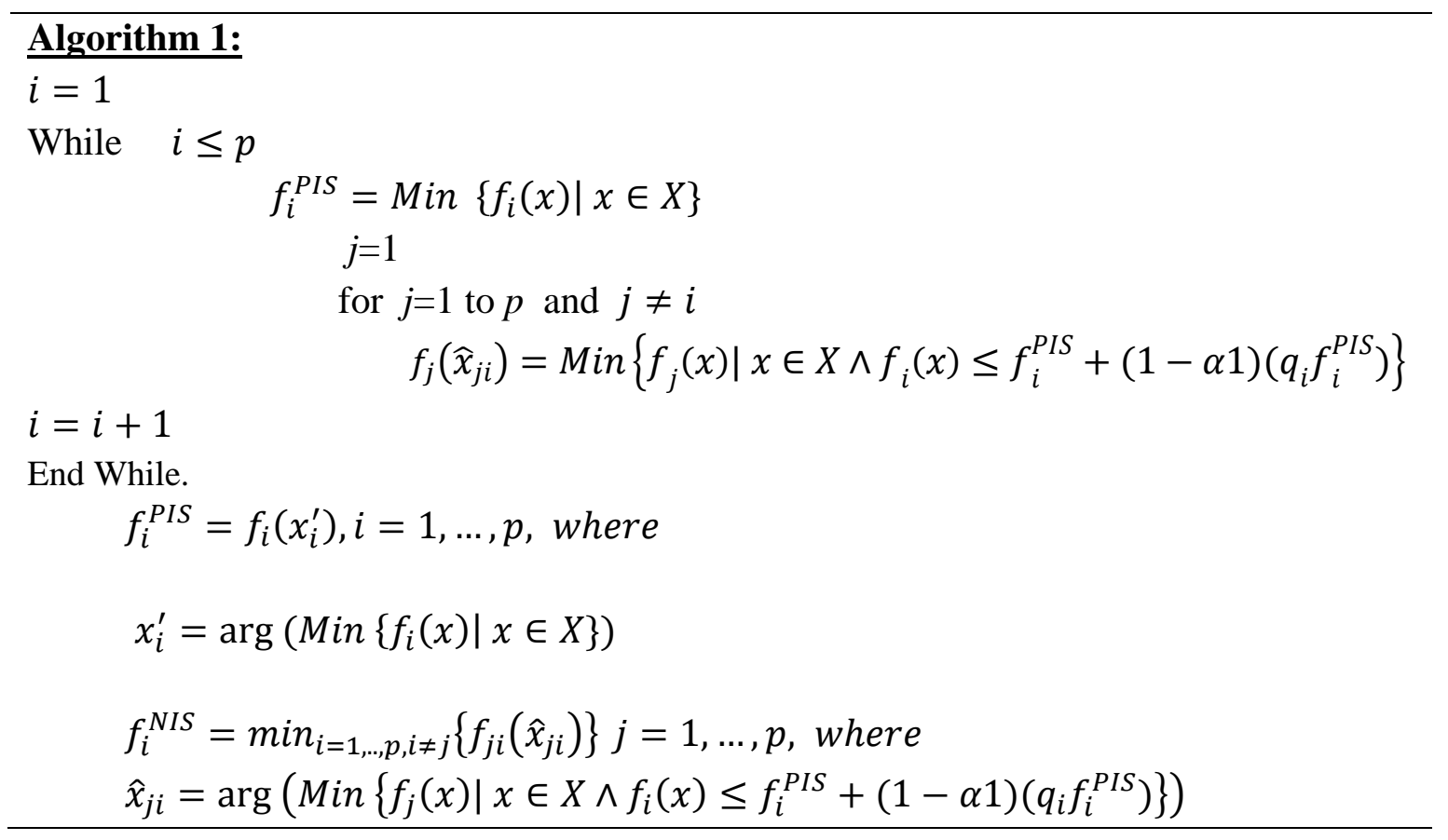


In algorithm 1, the relation for optimizing OF within the cycle command is the equivalent crisp form of the following flexible programming model (78) [70]:

$f_{j}\left(\hat{x}_{j i}\right)=\operatorname{Min}\left\{f_{j}(x) \mid x \in X \wedge f_{i}(x) \lesssim_{\sim \alpha 1} f_{i}^{P I S}\right\}$

In this way, unlike the traditional lexicographic method, the DM is allowed to determine the satisfaction degree $(\alpha 1)$ of violation of OFs from their optimal values $\left(f^{P I S}\right)$ by $q$ percent. After determining the ranges of each objective by algorithm 1 , the augmented $\varepsilon$-constraint approach is applied as follows [71]:

$\operatorname{Min}\left\{f_{1}(x)-\left(r_{1} \times \sum_{i=2}^{p} \frac{s_{i}}{r_{i}}\right) \mid x \in X \wedge f_{i}(x)+s_{i}=\varepsilon_{i} \wedge s_{i} \in R^{+}, \quad i=2, \ldots, p\right\}$

Where $r_{i}$ is the range of objective $i$ th and is calculated from pay-off table as $r_{i}=f_{i}^{N I S}-f_{i}^{P I S}$. In single optimization problem (79), the $f_{l}(\mathrm{x})$ is augmented by the second term. The augmented $\varepsilon$ constraint method generates only efficient solutions (see [66] for the proof). According to [66] increasing the amount of $\varepsilon$-vectors gradually, reduces the solution time of augmented $\varepsilon$ constraint method. Therefore, the proposed flexible lexicographic method for optimizing the ranges of OFs is computationally efficient than pure lexicographic method. The following steps summarize the proposed two-phased solution approach for the MO-PBSCND problem.

Step 1: Determine the satisfaction degree of constraints (i.e. $\alpha$ ) and use the principles described in Section 4, to convert the MO-PBSCND model to its equivalent crisp one.

Step 2: Determine the satisfaction degree of violation of OFs from their optimal values (i.e. $\alpha 1$ ) by $q$ percent based upon the DM preferences and apply the algorithm 1 to specify the ranges of each OF (i.e., $f_{i}^{P I S}, f_{i}^{N I S}$ ).

Step 3: Construct the $\varepsilon$-vectors according to the ranges obtained in step 2 for each OF. The following equation divides the range of each $\mathrm{OF}$ into $(m-1)$ equal intervals and generates $\varepsilon$ vectors for each $\mathrm{OF}$ :

$\varepsilon_{i}=f_{i}^{N I S}-\left(\frac{f_{i}^{N I S}-f_{i}^{P I S}}{m}\right) \times n, \quad n=0,1,2, \ldots, m$

The more the grid points, the more efficient solutions from the Pareto-optimal set are provided and thus the DM has the opportunity to select the most preferred solution after applying step 4. 
Step 4: Solve the augmented $\varepsilon$-constraint method (79) to find the efficient solutions from the Pareto-optimal set. If the DM is satisfied with the acquired efficient solutions, then stop otherwise go to step 3 and increase the number of grid points to find more efficient solutions.

\section{Case study}

To evaluate the performance and efficiency of the proposed MO-PBSCND model, a real case study is presented here. The case is conducted in Iran and the aim of this study is to determine the strategic and tactical level decisions related to biodiesel supply chain management under uncertainty.

Iran has a great potential for exploiting different biomass resources and energy crops such as sunflower, sorghum, sugar beet, switchgrass, and JCL. Indeed, there are good climate conditions and waste lands in Iran for prospering agriculture activities. In addition, Iran has useless extensive hectares of arid and semi-arid areas that could be exploited for cultivation of energy crops such as JCL that grows in marginal and infertile lands, efficiently. According to Jatroha belt $\left(30^{\circ} \mathrm{N}, 35^{\circ} \mathrm{S}\right)$, southern half of Iran is the most appropriate area for JCL cultivation. Considering the fact that Iran imports about 80 percent of its edible oil consumption, utilizing edible oils sources such as palm, corn, sunflower, soya, and cotton for biodiesel production is irrational and would be a menace for food supply resources. Therefore, exploiting other nonedible oil sources such as JCL and UCO can be a great opportunity for Iran. Another interesting source of biodiesel production in Iran is UCO, which is produced about 300,000 ton (t), annually. Currently, there is one bio-refinery producing biodiesel with mediocre capacity in Iran (Isfahan city). Iran is planning to increase generation of different types of renewable energies to reduce dependency on crude oil. Energy consumption evaluation in Iran shows a great increasing trend in renewable energy consumption [72]. In recent years, JCL has been cultivated in some southern cities of Iran in small scales to evaluate its yielding. The results indicate that JCL plants yield under 17 months of cultivation, while the average time to JCL yielding is about 24 months [73]. In this regard, to commercialize JCL cultivation and biodiesel production in Iran, a comprehensive decision making tool guaranteeing sustainable development is needed. This paper presents such decision making tool considering real world assumptions.

\subsection{Data gathering and environmental impact calculation}


As mentioned previously, the most important input parameters in the proposed MO-PBSCND model are considered to be fuzzy numbers and their behavior can be modeled by a triangular possibility distribution. In this paper, the most possible values of the fuzzy parameters are estimated by the available historical data and range of variation of fuzzy parameters are determined by experts' opinion. The most possible values of the most important fuzzy parameters used in the studied case are presented in Appendix C. It is worthy to note that all date are firstly estimated for each year and then to reduce computational complexity of the model, are aggregated into periods. The considered planning horizon is 21 years and 7 periods (each period includes 3 years). The all used data can be provided upon request.

To estimate the most possible values of biodiesel demands, first fossil diesel demands are predicted according to historical data. Then, the predetermined combination percentages of fossil diesel and biodiesel in different periods are used to estimate biodiesel demands (see Table C.1). Biodiesel demands in big cities (i.e., Tabriz, Isfahan, Khorasan R., Khozestan, and Fars) start with B2 type and reach B7.5 (92.5\% diesel and 7.5\% biodiesel) after planning horizon. This combination percentage for Tehran is B2.5-B10. Other cities are expected to reach B2.5 after planning horizon. This policy is assumed to reduce the high amount of greenhouse gases emitted due to higher fossil fuel combustion in big cities compared to other cities. Glycerin as a byproduct of transesterification process is used in producing hygienic products. 11 cities of Iran have factories producing hygienic products. About $75 \%$ of hygienic products are produced in Tehran. We assume that demand of glycerin in each city is consistent with the capacity of hygienic factory in that city. That is, the estimated produced glycerin is divided between 11 cities according to their capacity for producing hygienic products (see Table C.2). The amount of UCO produced in each city is provided from Iranian Fuel Conversion Company (www.ifco.ir). Table C. 3 represents the amount of UCO collected from all cities in different periods.

Fixed opening costs, variable opening costs, production and inventory holding costs are taken into account according to own calculations and previous feasibility studies performed in Iran. The calculated different costs vary between various cities according to their total price index. Price index is a weighted average of prices of a set of good and services in a given region and thus can be used for comparing costs in different cities. Also, these costs are estimated based on average annual inflation rate in Iran in upcoming years. Table C.5 and Table C.6 respectively demonstrate the costs of JCL cultivation and slope coefficients corresponding to breakpoints of 
cultivated area. Transportation cost between each two cities is calculated through multiplying unitary transportation cost by distance between them. Road and rail distances between different cities are provided from Ministry of Roads \& Urban Development (www.mrud.ir) and Asia Seir Aras Company (www.asiaseiraras.com), respectively.

Conversion factor of JCL yields to JCL oil is assumed to be 0.35 [5]. Conversion factor of collected UCO to purified UCO is assumed to be 0.95. Also, conversion factors of oils to biodiesel are considered to be 0.83 [44].

The most possible value of JCL yields $\left(\eta_{f t}\right)$ in different periods are extracted from [5]. Note that $\eta_{f t}$ is location and time period dependent. Locations with good ecological and soil conditions have higher amount of yields. It is worthy to note that JCL yields are altered from 2 to $12 \mathrm{t} / \mathrm{ha} / \mathrm{y}$ in the literature according to ecological and soil conditions [7, 74]. Since arid and semi-arid areas are considered as potential areas for JCL cultivation in the studied case, we assume the JCL yields are between 2 to $7 \mathrm{t} / \mathrm{ha} / \mathrm{y}$. In mild conditions like as our case, this amount of JCL yields is expected according to real experiences and scientific reports $[5,73]$. Also, we consider $3 \times 3 \mathrm{~m}^{2}$ space for cultivation of each JCL plant and so there would be about 1100 plants per hectare [5]. The most likely values of JCL yields are illustrated in Table C.4.

To calculate environmental impact (EI) of the all processes including from facilities establishment to biodiesel and glycerin distribution in the system boundary (see Fig.1), SimaPro 8 software (www.pre-sustainability.com) equipped with ecoinvent version3 database is used. SimaPro 8 is the comprehensive tool specified for EI assessment of different processes in industries. Also, ecoinvent v3 is the newest version of ecoinvent database recently released by the ecoinvent center (www.ecoinvent.org). Although exact EI of different processes are geographic location dependent, SimaPro 8 provides EI assessment under standard conditions which can be used in different zones without needing for LCA expert teams. The EIs of establishing facilities are calculated for the considered 21 years planning horizon. According to Goedkoop and Spriensma [17], EI's coefficients are considered as dimensionless. However, point $(\mathrm{Pt})$ is used as a name for EI dimension representing one thousandth of the yearly environmental load of one average European inhabitant.

It should be noted that some parameters such as EI of JCL cultivation are not available in SimaPro database or the inputs of some of processes in the studied case are not in standard conditions and have small difference respect to SimaPro database. Therefore, these parameters 
are calculated separately by defining new processes in SimaPro. Achten [75] has calculated the environmental impact of biodiesel production from JCL seeds. In [75], only the LCA of biodiesel production from JCL is evaluated and the EI of each process is not addressed. Meanwhile, the data presented in [75] is changed according to the conditions of the studied case and then EI of each process is calculated. The material required for producing 1 (t) JCL seeds and amount of emissions to air due to using NPK fertilizers are according to Table 1.

Table 1. Required inputs for producing 1 ton JCL seeds

\begin{tabular}{|c|c|c|c|c|c|}
\hline $\begin{array}{l}\text { Land }(3 \times 3 \\
\text { cultivation })\end{array}$ & $\begin{array}{l}\text { Land levelling } \\
\text { and } \\
\text { ploughing }\end{array}$ & Irrigation & $\begin{array}{l}\text { Fertilizers } \\
(\mathbf{N}, \mathbf{P}, \mathbf{K})\end{array}$ & Emissions to air & Pesticide \\
\hline $\begin{array}{c}0.324 \text { (ha) or } \\
357 \text { trees }\end{array}$ & $\begin{array}{l}\text { Tractor } \\
(6 \mathrm{~h} / \mathrm{ha})\end{array}$ & 5 (1/ha) & $\begin{array}{c}\mathrm{N}=74.68(\mathrm{~kg} / \mathrm{ha}) \\
\mathrm{P}=23.91 \\
\mathrm{~K}=50.09 \\
\text { And, } \\
\mathrm{N}=0.46 \mathrm{Urea} \\
\mathrm{P}=0.44 \mathrm{P}_{2} \mathrm{O}_{5} \\
\mathrm{~K}=0.83 \mathrm{~K}_{2} \mathrm{O} \\
\text { Thus (for } 0.324 \\
\text { (ha)): } \\
\mathrm{Urea}=52 \mathrm{~kg} \\
\mathrm{P}_{2} \mathrm{O}_{5}=17.6 \mathrm{~kg} \\
\mathrm{~K}_{2} \mathrm{O}=19.5 \mathrm{~kg}\end{array}$ & $\begin{array}{c}\mathrm{NO}_{3}=75.92 \\
(\mathrm{~kg} / \mathrm{ha}) \\
\mathrm{NH}_{3}=25.31 \\
\mathrm{~N}_{2} \mathrm{O}=2.53\end{array}$ & $\begin{array}{c}\text { Pyrethroid } \\
\text { compounds= } \\
0.0027 \\
(\mathrm{~kg} / \mathrm{ha})\end{array}$ \\
\hline
\end{tabular}

It is assumed that truck (28 ton) is used for road transportation and train consuming diesel as fuel is used for rail transportation purpose. These modes are common transportations modes for cargo shipment in Iran. In JCL oil extraction centers, the required inputs for producing 1 (t) JCL oil include $2.8(\mathrm{t}) \mathrm{JCL}$ seeds and $1756(\mathrm{kWh})$ electricity generated by natural gas with cold pressing technology. The most important point in calculating EI of JCL oil extraction process is that the EI of producing $2.8(\mathrm{t}) \mathrm{JCL}$ seeds must be excluded from the amount accounted in this phase. Really, the EI of producing JCL seeds has been calculated in the first phase and so should not be duplicated in this phase. The required inputs for biodiesel production by transesterification in the studied case are according to Table 2.

Table 2. Required inputs for producing 1 ton biodiesel

\begin{tabular}{|c|c|c|c|c|c|}
\hline Oil & Methanol & NAOH & Water & Electricity & Heat \\
\hline $1(\mathrm{t})$ & $0.205(\mathrm{t})$ & $0.012(\mathrm{t})$ & $0.01(\mathrm{t})$ & $0.704(\mathrm{kWh})$ & $0.508(\mathrm{Gcal})$ or $2125.5(\mathrm{MJ})$ \\
\hline
\end{tabular}

Other inputs for different processes in the studied case do not have significant difference respect to standard conditions described in SimaPro and hence can be directly calculated by the software 
database. Table C.7 shows the most likely values of EI of different processes in the studied case. Notably, EI values are subject to measurement error and other uncertainties such as geographic location conditions. Although SimaPro software provides sensitivity analysis for assessing the uncertainty of EI, to consider the effect of uncertainty of EI in optimizing sustainable SCs it should be considered in environmental OF. In this regard, we assume triangular possibility distribution to model the small perturbations of EI in the studied case.

\subsection{Results and discussions}

The proposed MO-PBSCND model is coded in GAMS ${ }^{\circledR}$ optimization software and solved by CPLEX solver. The global optimum solution is achieved under 3 hours for the proposed MOPBSCND model. Due to strategic level of decisions made by the proposed model, this amount of time for solving the proposed model is reasonable. Feasibility degree of constraints (i.e., $\alpha$ ) is assumed to be 0.8 in all computation. To assess the performance of the proposed new formulation of possibilistic programming method, the proposed model is separately solved for each cost and environmental OF for different values of risk coefficients (i.e. $\gamma$ ). Fig. 3 illustrates that by reducing risk factor via increasing values of $\gamma$ in the cost $\mathrm{OF}$, total mean cost value is increased. Indeed, the model opens more facilities or installs more capacities to deal with the risk of uncertain parameters for higher values of $\gamma$. This behavior is observed for possibilistic mean and absolute deviation of environmental OF (see Fig. 4). However, the sensitivity of cost OF to $\gamma$ values is higher than environmental OF. This observation could be justified due to low perturbation of fuzzy EI of different processes in the environmental OF. The DM can determine the desire $\gamma$ value according to risk and cost importance. Obviously, risk-averse organizations prefer higher values of $\gamma$. The risk coefficients for cost and environmental OFs (i.e., $\gamma$ values) in solving the MO-PBSCND problem are considered to be 3 for both of them. 


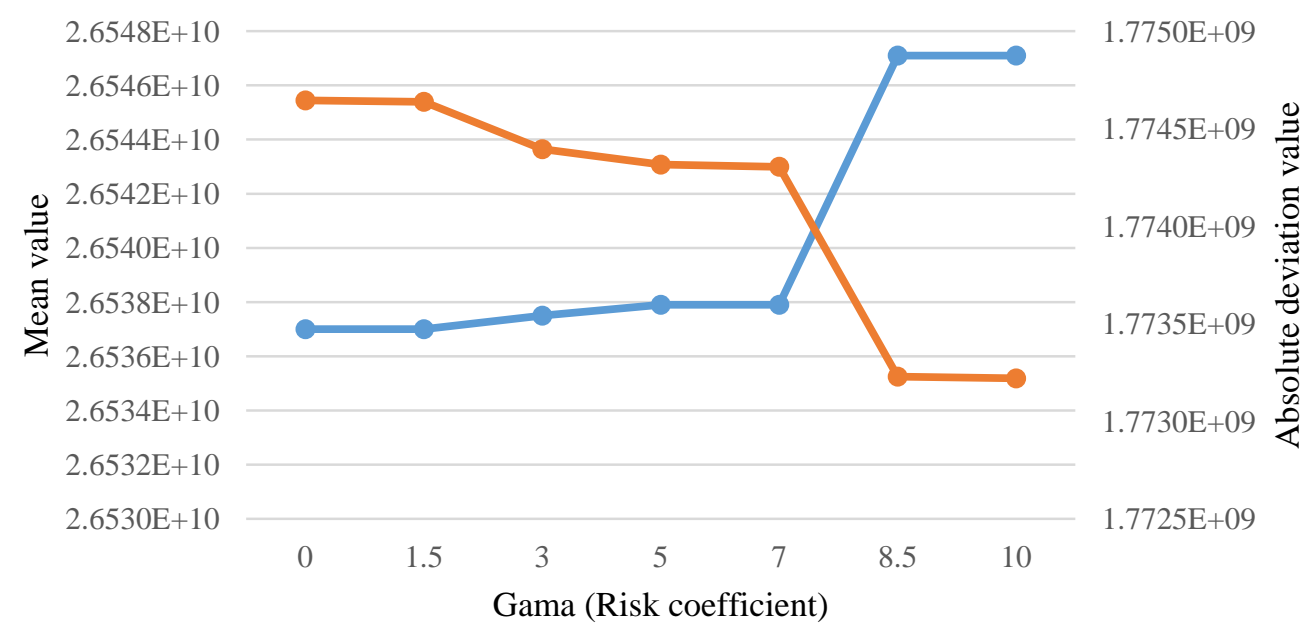

- Mean value $\quad$ Absolute deviation value

Fig. 3. Possibilistic Mean value vs. possibilistic absolute deviation in cost OF for different values of Gama at feasibility degree of 0.8

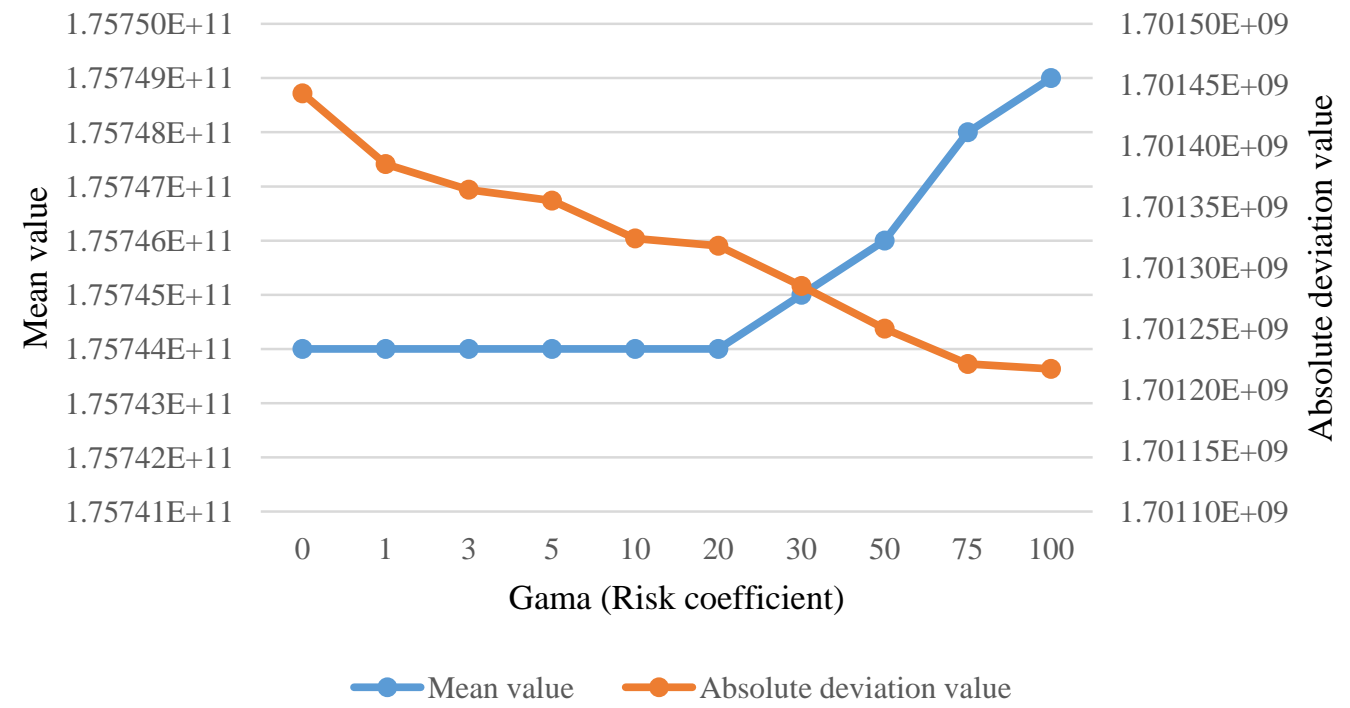

Fig. 4. Possibilistic Mean value vs. possibilistic absolute deviation in environmental OF for different values of Gama at feasibility degree of 0.8

It is worthy to note that if only mean value of fuzzy parameters is used in the OFs (i.e., $\gamma=0$ ), lower total cost is achieved compared to the proposed possibilistic approach. However, variation of total cost will be increased under realization of uncertain parameters (see [76]). Indeed, robustness of the solution is not controllable by using only mean values of fuzzy parameters. Meanwhile, the proposed approach can appropriately control the robustness of solutions 
according to DM preferences. Figure 3 and Figure 4 show that the possibilistic absolute deviation has the highest value when the mean value approach is applied. That is, risk of decision making by using the mean value approach is very high.

To solve the proposed MO-PBSCND model, first the pay-off table is constructed. Table 3 demonstrates the pay-off table for different values of satisfaction degrees of violation OFs from their optimal values by $q=5$ percent. The proposed flexible lexicographic method is used to construct pay-off table.

Table 3. Pay-off table for the OFs

\begin{tabular}{|c|c|c|c|c|c|}
\hline \multicolumn{2}{|c|}{$\alpha 1=1$} & \multicolumn{2}{c|}{$\alpha 1=0.9$} & \multicolumn{2}{c|}{$\alpha 1=0.8$} \\
\hline OF1 & OF2 & OF1 & OF2 & OF1 & OF2 \\
\hline $3.186 \mathrm{E}+10$ & $2.029 \mathrm{E}+11$ & $3.186 \mathrm{E}+10$ & $2.023 \mathrm{E}+11$ & $3.186 \mathrm{E}+10$ & $2.017 \mathrm{E}+11$ \\
\hline $8.295 \mathrm{E}+13$ & $1.808 \mathrm{E}+11$ & $4.035 \mathrm{E}+10$ & $1.808 \mathrm{E}+11$ & $3.996 \mathrm{E}+10$ & $1.808 \mathrm{E}+11$ \\
\hline
\end{tabular}

In this paper, the obtained ranges of OFs at satisfaction degree of 0.9 (i.e. $\alpha 1=0.9$ ) are used in the augmented $\varepsilon$-constraint method to find efficient solutions from the Pareto-optimal set. Fig. 5 shows the efficient solutions obtained for the proposed MO-PBSCND problem by the augmented $\varepsilon$-constraint method. This figure indicates that minimization of cost OF and environmental OF are in conflict with each other. Therefore, the DM can select the most preferred solution from the provided efficient solutions. To select an efficient solution from the Pareto-optimal set, at first some efficient solutions are selected from the total span of Pareto-optimal set. If the DM is not satisfied with these solution, $\varepsilon$-vectors are changed to produce more efficient solutions. These process is iteratively performed until the most preferred solution is selected [77].The DM may consider environmental regulations and budget limitation in selecting the most preferred solution. 


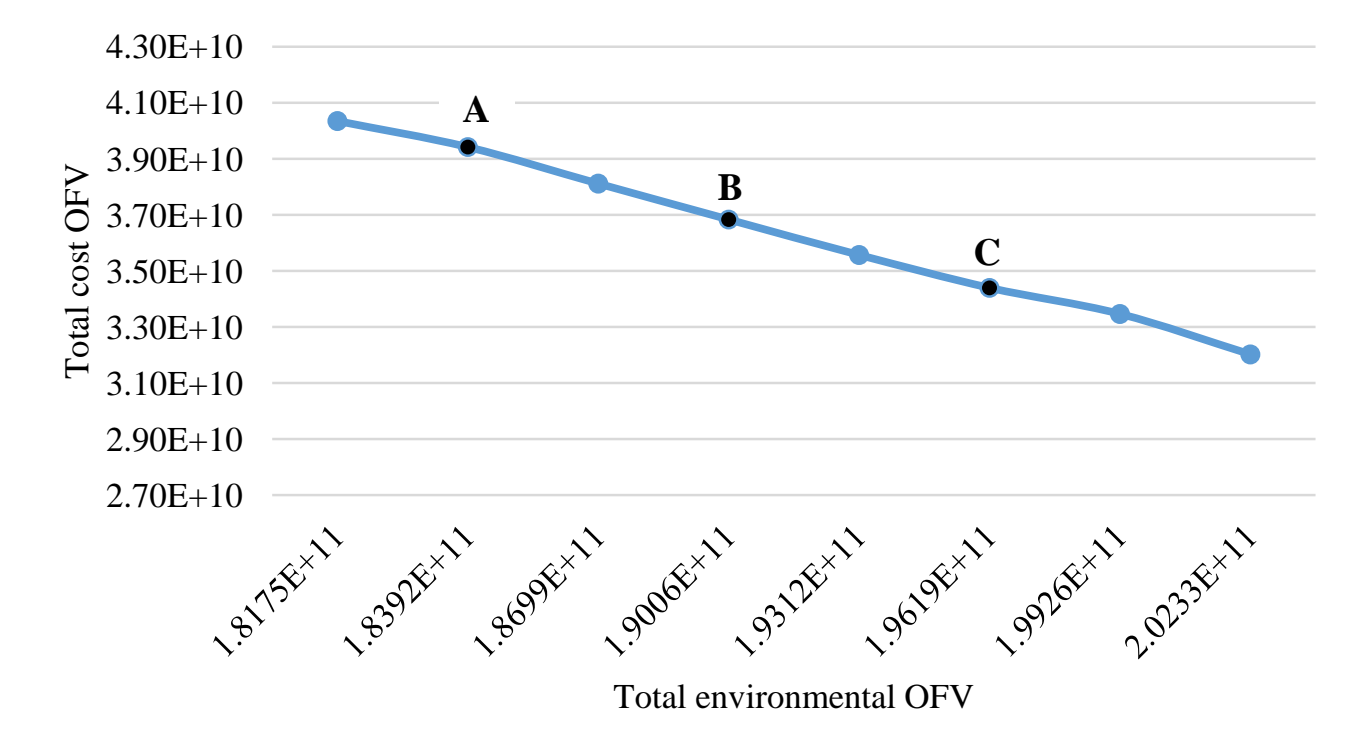

Fig. 5. Trade-off between cost $\mathrm{OF}$ and environmental OF

The mean and absolute deviation of OFs corresponding to efficient points of Fig. 5 are shown in Table 4.

Table 4. Mean and absolute deviation of the considered OFs

\begin{tabular}{|c|l|l|l|l|l|l|l|l|l|}
\hline \multirow{2}{*}{$\begin{array}{c}\text { Cost } \\
\text { OF }\end{array}$} & Mean & $2.67 \mathrm{E}+10$ & $2.78 \mathrm{E}+10$ & $2.86 \mathrm{E}+10$ & $2.95 \mathrm{E}+10$ & $3.05 \mathrm{E}+10$ & $3.15 \mathrm{E}+10$ & $3.26 \mathrm{E}+10$ & $3.33 \mathrm{E}+10$ \\
\cline { 2 - 11 } & Dev. & $1.78 \mathrm{E}+09$ & $1.88 \mathrm{E}+09$ & $1.94 \mathrm{E}+09$ & $2.02 \mathrm{E}+09$ & $2.1 \mathrm{E}+09$ & $2.19 \mathrm{E}+09$ & $2.28 \mathrm{E}+09$ & $2.34 \mathrm{E}+09$ \\
\hline \multirow{2}{*}{$\begin{array}{l}\text { Env. } \\
\text { OF }\end{array}$} & Mean & $1.97 \mathrm{E}+11$ & $1.93 \mathrm{E}+11$ & $1.91 \mathrm{E}+11$ & $1.88 \mathrm{E}+11$ & $1.85 \mathrm{E}+11$ & $1.82 \mathrm{E}+11$ & $1.79 \mathrm{E}+11$ & $1.77 \mathrm{E}+11$ \\
\cline { 2 - 11 } & Dev. & $1.85 \mathrm{E}+09$ & $1.83 \mathrm{E}+09$ & $1.81 \mathrm{E}+09$ & $1.80 \mathrm{E}+09$ & $1.78 \mathrm{E}+09$ & $1.76 \mathrm{E}+09$ & $1.74 \mathrm{E}+09$ & $1.71 \mathrm{E}+09$ \\
\hline
\end{tabular}

Mean values of cost and environmental objective function's components are illustrated for one of the efficient solutions of Fig. 5 (i.e., point B) in Tables 5 and 6, respectively. Table 7 compares the values of binary variables and material flow within the constructed biodiesel SC network between efficient solutions $\mathrm{A}$ and $\mathrm{C}$ of Fig. 5. According to this table, points $\mathrm{A}$ and $\mathrm{C}$ lead to different values for binary variables $u$ and $y$, but the same values for variables $x, v$, and $w$. In solution $\mathrm{C}$, the total amount of established capacities in all echelons of the biodiesel SC is more than that of point A. Also, the material flow transported by road or rail mode within the constructed biodiesel SC in solution $\mathrm{C}$ is more than that of solution A. This observation shows that solution $\mathrm{C}$ leads to a biodiesel SC that has more degree of decentralization compared to solution A. Although the rail transportation mode has lower EI compared to road one, the total material flow by road mode is higher than that of rail mode in solutions $\mathrm{A}$ and $\mathrm{C}$. This could be justified due to the fact that rail transportation mode is available among limited number of cities 
in Iran while all cities are linked together by road transportation mode. Also, the model prefers to establish more facilities in different echelons to decrease total transportation cost.

Table 5. Cost objective function's components (Mean values)

\begin{tabular}{cccccc}
\hline $\begin{array}{c}\text { Fixed opening } \\
\text { costs }\end{array}$ & $\begin{array}{c}\text { Variable } \\
\text { opening costs }\end{array}$ & $\begin{array}{c}\text { Production } \\
\text { costs }\end{array}$ & $\begin{array}{c}\text { Inventory } \\
\text { holding costs }\end{array}$ & $\begin{array}{c}\text { Transportation } \\
\text { costs }\end{array}$ & $\begin{array}{c}\text { Importing } \\
\text { costs }\end{array}$ \\
\hline $2.6920 \mathrm{E}+5$ & $8.7763 \mathrm{E}+9$ & $3.4242 \mathrm{E}+9$ & $1.4357 \mathrm{E}+7$ & $1.831 \mathrm{E}+10$ & $1.796 \mathrm{E}+10$ \\
\hline
\end{tabular}

Table 6. Environmental objective function's components (Mean values)

\begin{tabular}{ccccc}
\hline Facility establishment & Production & $\begin{array}{c}\text { Inventory } \\
\text { holding }\end{array}$ & Transportation & Importing \\
\hline $1.380 \mathrm{E}+11$ & $3.922 \mathrm{E}+10$ & $3.7289 \mathrm{E}+8$ & $6.9740 \mathrm{E}+7$ & $7.0598 \mathrm{E}+9$ \\
\hline
\end{tabular}

Table 7. Comparison of efficient solutions A and C

\begin{tabular}{ccc}
\hline Variables & Point A & Point C \\
\hline$x$ & $4,5,7,15,17$ & $4,5,7,15,17$ \\
$u$ & $4,7,8,10,11,18,19,21$ & $4,7,8,10,17,18,19,21$ \\
$y$ & $1,4,10,13,15,18,20,22,25,26,28,29$ & $1,4,7,10,15,18,20,22,25,26,28,29$ \\
$v$ & $1,4,10,18,29$ & $1,4,10,18,29$ \\
$w$ & $1,4,8,10,11,13,18,27,29$ & $1,4,8,10,11,13,18,27,29$ \\
Capacity & $8.607142 \mathrm{E}+7$ & $8.966031 \mathrm{E}+7$ \\
Road flow & $8.236684 \mathrm{E}+7$ & $8.359109 \mathrm{E}+7$ \\
Rail flow & $3.248608 \mathrm{E}+7$ & $3.485216 \mathrm{E}+7$ \\
\hline
\end{tabular}

It should be noted that most of the studies in the literature assessing the environmental impact of biofuel SCs have ignored the environmental impact of facilities establishment and related capacity installation $[32,33,34]$. The acquired results show that EI of facilities establishment have the major share in environmental OF (see Table 6) and therefore should be considered in designing sustainable biofuel SCs.

\section{Conclusions}

In this paper, a MO-PBSCND model is developed for sustainable design of second-generation biodiesel SC from non-edible feedstocks JCL and UCO under risk aiming to minimize total cost and EI of different involved processes. The proposed model is a MINLP one which is converted 
to an equivalent MILP model through appropriate linearization techniques. The developed model integrates upstream and downstream sections of biodiesel SC and determines related strategic and tactical level decisions such as location/allocation decisions, capacity of established facilities, inventory holding, production and import planning, and transportation modes under real-life assumptions. As mentioned previously, biofuel SCs are more vulnerable to risk compared to traditional SCs and therefore suitable risk management tools should be applied in biofuel SCs optimization under uncertainty. In this study, a new formulation of possibilistic programming approach based on definition of possibilistic mean and absolute deviation of fuzzy numbers is presented being able to minimize the mean and risk values of OFs under possibilisticbased uncertainty. To solve the proposed MO-PBSCND model a solution method based-on hybrid flexible lexicographic and augmented $\varepsilon$-constraint methods is proposed being able to find only efficient solutions from the Pareto-optimal set. Application of the proposed model in a real case in Iran demonstrates the usefulness and applicability of the proposed model and solution approaches for risk management. Also, the results show that for sustainable design of biofuel SCs, EI of all involved processes from facility establishment to final distribution of end products should be considered in environmental assessment process. Cost and environmental analysis states that for more improvement of environmental burdens of the considered biodiesel SC, the more costs should be invested. Also, higher cost is required to reduce the risk resulted from uncertain input parameters. The trade-off among minimization of total costs, risk factor and EI can be performed according to management preferences and legislation limitations. Other conclusion is that risk-neutral approaches could not be suitable tools for optimizing biofuel SCs under uncertainty. Additionally, applying scenario-based stochastic programming methods needs reliable historical data and increases the computational complexity of such problems and hence could not be used in modeling real-life large cases. In contrast, the proposed approach controls the risk levels of uncertain parameters without increasing computational efforts. The future research could be followed through employing the proposed method for dealing with the uncertainty in optimizing bioethanol SC under uncertainty. Also, local logistics optimization of feedstock from fields to cities could be hierarchically integrated with the proposed model to determine the optimum values of decisions in local logistics optimization problem.

\section{Acknowledgement}


The authors would like to acknowledge the Iran National Science Foundation (INSF) for the financial support of this study. Also, we are grateful for the efforts of the editor and referees as they helped us to improve the presentation of the paper, significantly.

\section{Appendix A.}

\section{Indices}

$f \quad$ Index of candidate locations for JCL cultivation centers

$g \quad$ Index of candidate locations for UCO supply centers

$i \quad$ Index of candidate locations for collection and oil extraction centers of JCL yields

$s \quad$ Index of candidate locations for collection and pre-treatment centers of UCO

$j \quad$ Index of candidate locations for bio-refinery centers of biodiesel production

$k \quad$ Index of candidate locations for storage and distribution centers of biodiesel

$c \quad$ Index of consumer centers of biodiesel

$n \quad$ Index of consumer centers of glycerin

$l \quad$ Index of transportation mode (road and railway)

$t \quad$ Index of time period

\section{Technical parameters}

$\widetilde{D}_{c t} \quad$ Demand of consumer center $c$ for biodiesel in period $t$ (ton/period)

$\widetilde{D} E_{n t} \quad$ Demand of consumer center $n$ for glycerin in period $t$ (ton/period)

$\widetilde{W} O_{g t} \quad$ Amount of UCO supplied by supply center $g$ in period $t$ (ton/period)

$\tilde{\eta}_{f t} \quad$ Amount of JCL yields per hectare at location $f$ in period $t$ (ton/ha)

$\varphi \quad$ Conversion factor of JCL yields to JCL oil (percent)

$\beta \quad$ Conversion factor of collected UCO to pre-treated UCO (percent)

$\pi \quad$ Conversion factor of JCL oil to biodiesel (percent)

$\omega \quad$ Conversion factor of pre-treated UCO to biodiesel (percent)

$L A_{f} \quad$ Minimum land area dedicated for JCL cultivation center at location $f$ (ha ${ }^{*}$ )

$U A_{f} \quad$ Maximum land area available for JCL cultivation center at location $f$ (ha)

$L C_{i} \quad$ Lower bound dedicated on capacity of collection and oil extraction center of JCL yields at location $i$ (ton)

$U C_{i} \quad$ Upper bound of capacity of collection and oil extraction center of JCL yields at location $i$ (ton)

$L W_{s} \quad$ Lower bound dedicated on capacity of collection and pre-treatment center of UCO at 
location $s$ (ton)

$U W_{s} \quad$ Upper bound of capacity of collection and pre-treatment center of UCO at location $s$ (ton)

$L B_{j} \quad$ Lower bound dedicated on capacity of bio-refinery center at location $j$ (ton)

$U B_{j} \quad$ Upper bound of capacity of bio-refinery center at location $j$ (ton)

$L S_{k} \quad$ Lower bound dedicated on capacity of storage and distribution center at location $k$ (ton)

$U S_{k} \quad$ Upper bound of capacity of storage and distribution center at location $k$ (ton)

Maxx Maximum number of areas which can be selected for JCL cultivation

Maxy Maximum number of locations which can be selected for opening collection and pretreatment center of UCO

Maxu Maximum number of locations which can be selected for opening collection and oil extraction center of JCL seeds

Maxv Maximum number of locations which can be selected for opening bio-refinery

Maxw

Maximum number of locations which can be selected for opening storage and distribution center of biodiesel

$\operatorname{MaxIm}_{i t} \quad$ Maximum amount of JCL seeds could be imported in oil extraction center $i$ in period $t$

$D_{i s} J T_{f l i} \quad$ Distance between cultivation center $f$ and oil extraction center $i$ by mode $l$

$D i s W T_{g l s} \quad$ Distance between UCO supply center $g$ and collection center $s$ by mode $l$

$D_{i s} O T_{i l j} \quad$ Distance between JCL oil extraction center $i$ and bio-refinery $j$ by model $l$

$D_{i s} V T_{s l j} \quad$ Distance between UCO collection center $s$ and bio-refinery $j$ by mode $l$

$D i s B T_{j l k} \quad$ Distance between bio-refinery $j$ and distribution center $k$ by mode $l$

$D i s G T_{j l n} \quad$ Distance between bio-refinery $j$ and consumer center $n$ by mode $l$

$D_{i s M T}$ Distance between distribution center $k$ and consumer center $c$ by mode $l$

\section{Cost parameters}

$F \tilde{C} J_{f t} \quad$ Fixed cost of JCL cultivation at location $f$ in period $t\left(\mathrm{MIRR}^{*} / \mathrm{period}\right)$

$F \tilde{C} C_{i t} \quad$ Fixed cost of opening oil extraction center of JCL seeds at location $i$ in period $t$

$F \tilde{C} W_{s t} \quad$ Fixed cost of opening collection center of UCO at location $s$ in period $t$

$F \tilde{C} B_{j t} \quad$ Fixed cost of opening bio-refinery center at location $j$ in period $t$

$F \tilde{C} S_{k t} \quad$ Fixed cost of opening distribution center at location $k$ in period $t$

$V \tilde{C} J_{f} \quad$ Variable cost of JCL cultivation per hectare at location $f(\mathrm{MIRR} / \mathrm{ha})$

$V \tilde{C} C_{i t} \quad$ Variable cost per unit capacity for oil extraction center of JCL seeds at location $i$ in period $t$ (MIRR. $\operatorname{ton}^{-1} /$ period)

$V \tilde{C} W_{s t} \quad$ Variable cost per unit capacity for collection center of UCO $s$ in period $t$ (MIRR.ton 
$1 /$ period)

$V \tilde{C} B_{j t} \quad$ Variable cost per unit capacity for bio-refinery center $j$ in period $t$ (MIRR.ton ${ }^{-1} /$ period)

$V \tilde{C} S_{k t} \quad$ Variable cost per unit capacity for distribution center $k$ in period $t$ (MIRR.ton ${ }^{-1} /$ period)

$P \tilde{C} J_{f t} \quad$ Unit production cost of JCL seeds at location $f$ in period $t$ (MIRR.ha ${ }^{-1} /$ period)

$P \tilde{C} B_{j t} \quad$ Unit production cost of biodiesel at bio-refinery center $j$ in period $t$ (MIRR.ton ${ }^{-1} /$ period)

$P \tilde{C} G_{j t} \quad$ Unit production cost of glycerin at bio-refinery center $j$ in period $t$ (MIRR. $\operatorname{ton}^{-1} /$ period)

$P \tilde{C} O_{i t} \quad$ Unit oil extraction cost from JCL seeds in oil extraction center $i$ in period $t$ (MIRR.ton $1 /$ period)

$P \tilde{C} W_{s t} \quad$ Unit purifying cost of UCO at collection center $s$ in period $t$ (MIRR.ton ${ }^{-1} /$ period)

$P \tilde{C} C_{g t} \quad$ Unit collection cost of UCO at supply center $g$ in period $t$ (MIRR.ton ${ }^{-1} /$ period)

$I \tilde{C} J_{i t} \quad \begin{array}{ll}\text { Unit inven } \\ \text { period) }\end{array}$

$I \tilde{C} W_{s t} \quad$ Unit inventory holding cost of UCO at collection center $s$ in period $t$ (MIRR.ton ${ }^{-1} /$ period)

$I \tilde{C} B_{j t} \quad$ Unit inventory holding cost of biodiesel at bio-refinery center $j$ in period $t$ (MIRR.ton $1 /$ period)

$I \tilde{C} G_{j t} \quad$ Unit inventory holding cost of glycerin at bio-refinery center $j$ in period $t$ (MIRR.ton $1 /$ period)

IC $S_{k t} \quad$ Unit inventory holding cost of biodiesel at distribution center $k$ in period $t$ (MIRR.ton $1 /$ period)

$J \tilde{C} T_{\text {flit }} \quad$ Transportation cost of JCL seeds from cultivation center $f$ to oil extraction center $i$ by mode $l$ in period $t$ (MIRR.ton ${ }^{-1} /$ period)

$W \tilde{C} T_{g l s t} \quad$ Transportation cost of UCO from supply center $g$ to collection center $s$ by mode $l$ in period $t$ (MIRR.ton ${ }^{-1} /$ period)

$O \tilde{C} T_{i l j t} \quad$ Transportation cost of JCL oil from oil extraction center $i$ to bio-refinery $j$ by model $l$ in period $t$ (MIRR.ton ${ }^{-1} /$ period)

$V \tilde{C} T_{s l i t} \quad$ Transportation cost of pre-treated UCO from collection center $s$ to bio-refinery $j$ by mode $l$ in period $t$ (MIRR.ton ${ }^{-1} /$ period)

$\begin{array}{ll}B \tilde{C} T_{j k t} & \text { Transportation cost of biodiese } \\ & \text { period } t\left(\text { MIRR. } \operatorname{ton}^{-1} / \text { period }\right)\end{array}$

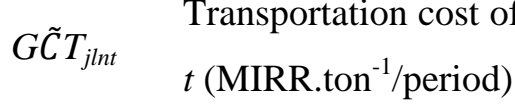
$\begin{array}{ll}M \tilde{C} T_{k l c t} & \text { Transportation cost of biodiesel from distribution center } k \text { to consumer center } c \text { by mode } l \text { in } \\ \text { period } t \text { (MIRR.ton }{ }^{-1} / \text { period) }\end{array}$ 
$C \tilde{I} m_{i t} \quad$ Importing cost of JCL seeds in oil extraction center $i$ in period $t$ (MIRR. $\operatorname{ton}^{-1} /$ period)

\section{Environmental parameters}

$\tilde{e} x_{f}$

$\tilde{e} y_{s}$

$\tilde{e} u_{i}$

$\tilde{e} v_{j}$

$\tilde{e} w_{k}$

$\tilde{E} B_{j} \quad$ Environmental impact of producing 1 ton biodiesel at bio-refinery center $j$

$\tilde{E} G_{j} \quad$ Environmental impact of producing 1 ton glycerin at bio-refinery center $j$

$\tilde{E} O_{i} \quad$ Environmental impact of producing 1 ton JCL oil at oil extraction center $i$

$\tilde{E} W_{s} \quad$ Environmental impact of purifying 1 ton $\mathrm{UCO}$ at location $s$

$\tilde{E} C_{g} \quad$ Environmental impact of collecting 1 ton UCO at supply center $g$

$E \tilde{I} J_{i} \quad$ Environmental impact of inventory holding of JCL seeds at oil extraction center $i$

$E \tilde{I} W_{s} \quad$ Environmental impact of inventory holding of UCO at collection center $s$

$E \tilde{I} B_{j} \quad$ Environmental impact of inventory holding of biodiesel at bio-refinery center $j$

$E I G_{j} \quad$ Environmental impact of inventory holding of glycerin at bio-refinery center $j$

$E \tilde{I} S_{k} \quad$ Environmental impact of inventory holding of biodiesel at distribution center $k$

$E \tilde{J} T_{f l i}$

$E \widetilde{W} T_{g l s}$

$E \tilde{O} T_{i l j}$

$E \tilde{V} T_{s l j}$

$E \tilde{B} T_{j l k}$
Environmental impact of transporting 1 ton JCL seeds per km from cultivation center $f$ to oil extraction center $i$ by mode $l$

Environmental impact of transporting 1 ton UCO per km from supply center $g$ to collection center $s$ by mode $l$

Environmental impact of transporting 1 ton JCL oil per km from oil extraction center $i$ to bio-refinery $j$ by model $l$

Environmental impact of transporting 1 ton UCO per $\mathrm{km}$ from collection center $s$ to biorefinery $j$ by mode $l$

Environmental impact of transporting 1 ton biodiesel per $\mathrm{km}$ from bio-refinery $j$ to distribution center $k$ by mode $l$ 
Environmental impact of transporting 1 ton glycerin per km from bio-refinery $j$ to consumer center $n$ by mode $l$

$E \widetilde{M} T_{k l c} \quad$ Environmental impact of transporting 1 ton biodiesel per $\mathrm{km}$ from distribution center $k$ to consumer center $m$ by mode $l$

$E \tilde{I} m_{i} \quad$ Environmental impact of importing 1 ton JCL seeds imported in oil extraction center $i$

\section{Binary decision variables}

$x_{f} \quad 1$ if location $f$ is selected for JCL cultivation; 0 otherwise

1 if location $s$ is selected for opening collection and pre-treatment center of UCO; 0

$y_{s} \quad$ otherwise

$u_{i}$ 1 if location $i$ is selected for opening collection and oil extraction center of JCL yields; 0 otherwise

$v_{j} \quad 1$ if location $j$ is selected for opening bio-refinery; 0 otherwise

$w_{k}$

1 if location $k$ is selected for opening storage and distribution center of biodiesel; 0 otherwise

\section{Continuous decision variables}

$I J_{i t} \quad$ Inventory level of JCL yields at collection and oil extraction center $i$ in period $t$ (ton/period)

$\operatorname{Im}_{i t}$ Amount of JCL yields imported at collection and oil extraction center $i$ in period $t$ (ton/period)

$I W_{s t} \quad$ Inventory level of UCO at collection and pre-treatment center $s$ in period $t$ (ton/period)

$I B_{j t} \quad$ Inventory level of biodiesel at bio-refinery $j$ in period $t$ (ton/period)

$I G_{j t} \quad$ Inventory level of glycerin at bio-refinery $j$ in period $t$ (ton/period)

$I S_{k t} \quad$ Inventory level of biodiesel at storage and distribution center $k$ in period $t$ (ton/period)

$P J_{f t} \quad$ Produced amount of JCL at cultivation center $f$ in period $t$ (ton/period)

$P B_{j t} \quad$ Produced amount of biodiesel at bio-refinery $j$ in period $t$ (ton/period)

$P G_{j t} \quad$ Produced amount of glycerin at bio-refinery $j$ in period $t$ (ton/period)

$P O_{i t} \quad$ Produced amount of JCL oil at collection and oil extraction center $i$ in period $t$ (ton/period)

$P W_{s t} \quad$ Produced amount of pre-treated UCO at collection and pre-treatment center $s$ in period $t$ (ton/period)

$J T_{\text {flit }} \quad$ Transported amount of JCL yields from

$W T_{g l s t} \quad$ Transported amount of UCO from supply center $g$ to collection and pre-treatment center $s$ by mode $l$ in period $t$ (ton/period) 

$O T_{i l j t} \quad$ Transported amount of JCL oil from collection and oil extraction center $i$ to bio-refinery $j$ by model $l$ in period $t$ (ton/period)
$V T_{s l j t} \quad$ Transported amount of pre-treated UCO from collection and pre-treatment center $s$ to bio- refinery $j$ by mode $l$ in period $t$ (ton/period)
$B T_{j l k t} \quad$ Transported amount of biodiesel from bio-refinery $j$ to storage and distribution center $k$ by mode $l$ in period $t$ (ton/period)
$G T_{j l n t}$ Transported amount of glycerin from bio-refinery $j$ to consumer center $n$ by mode $l$ in period $t$ (ton/period)
$M T_{k l c t} \quad$ Transported amount of biodiesel from storage and distribution center $k$ to consumer center $c$ by mode $l$ in period $t$ (ton/period)
$C J_{f} \quad$ Amount of cultivated area of JCL at location $f($ ha)
$C C_{i t} \quad$ Total capacity of collection and oil extraction center $i$ in period $t$ (ton)
$C E C_{i t} \quad$ Amount of capacity expansion at collection and oil extraction center $i$ in period $t$ (ton)
$C W_{s t} \quad$ Total capacity of collection and pre-treatment center $s$ in period $t$ (ton)
$C E W_{s t} \quad$ Amount of capacity expansion at collection and pre-treatment center $s$ in period $t$ (ton)
$C B_{j t} \quad$ Total capacity of bio-refinery $j$ in period $t$ (ton)
$C E B_{j t} \quad$ Amount of capacity expansion at bio-refinery $j$ in period $t$ (ton)
$C S_{k t} \quad$ Total capacity of storage and distribution center $k$ in period $t$ (ton)
$C E S_{k t} \quad$ Amount of capacity expansion at storage and distribution center $k$ in period $t$ (ton)

*MIRR (Million Iranian rials), ha (hectare), Pt (Point)

\section{Appendix B.}

Assume that $\tilde{c}$ is a triangular fuzzy number. Possibility distribution of fuzzy number $\tilde{c}$ is specified by its three prominent points, i.e., $\tilde{c}=\left(c^{p}, c^{m}, c^{o}\right)$, where $c^{\mathrm{p}}, c^{\mathrm{m}}$, and $c^{\mathrm{o}}$ represent the most pessimistic value, the most possible value, and the most optimistic value, respectively. These values are estimated through DM preferences and some available historical data. The membership function of $\tilde{c}$ is defined as follows: 


$$
\mu_{\tilde{c}}(x)= \begin{cases}0 & \text { if } x \in\left(-\infty, c^{p}\right] \\ f_{c}(x)=\frac{x-c^{p}}{c^{m}-c^{p}} & \text { if } x \in\left[c^{p}, c^{m}\right] \\ 1 & \text { if } x=c^{m} \\ g_{c}(x)=\frac{c^{o}-x}{c^{o}-c^{m}} & \text { if } x \in\left[c^{m}, c^{o}\right] \\ 0 & \text { if } x \in\left[c^{o},+\infty\right)\end{cases}
$$

The $\alpha$-cut of fuzzy number $\tilde{c}$ can be defined as $c_{\alpha}=\left\{x \in \Omega \mid \mu_{\tilde{c}}(x) \geq \alpha\right\} \quad \forall \alpha \epsilon[0,1]$, where $\Omega$ is the universe set. Since $\mu_{\tilde{c}}$ is continuous, the $\alpha$-cuts are closed and bounded. Therefore, they could be presented as:

$$
c_{\alpha}=\left[f_{c}^{-1}(\alpha), g_{c}^{-1}(\alpha)\right]=\left[c^{p}+\left(c^{m}-c^{p}\right) \alpha, c^{o}-\left(c^{o}-c^{m}\right) \alpha\right] .
$$

According to [59], the lower and upper possibilistic mean values of fuzzy number $\tilde{c}$ can be defined as follows:

$$
\begin{aligned}
& M_{1}(\tilde{c})=2 \int_{0}^{1} \alpha f_{c}^{-1}(\alpha) d \alpha=\frac{2}{3} c^{m}+\frac{1}{3} c^{p} \\
& M_{2}(\tilde{c})=2 \int_{0}^{1} \alpha g_{c}^{-1}(\alpha) d \alpha=\frac{2}{3} c^{m}+\frac{1}{3} c^{o}
\end{aligned}
$$

Accordingly, the interval-valued possibilistic mean of $\tilde{c}$ is stated as follows:

$$
M(\tilde{c})=\left[M_{1}(\tilde{c}), M_{2}(\tilde{c})\right]
$$

The possibilistic mean of fuzzy number $\tilde{c}$ is the half point of its interval-valued mean. Thus, the crisp possibilistic mean of $\tilde{c}$ is calculated as follows:

$$
\bar{M}(\tilde{c})=\frac{M_{1}(\tilde{c})+M_{2}(\tilde{c})}{2}=\frac{c^{p}+4 c^{m}+c^{o}}{6}
$$

It is evident from Equations (B.2) to (B.5) that in definition of possibilistic mean values of fuzzy numbers, points with small membership degrees are assumed to be less important and in contrast the most possibilistic values have higher degree of importance due to having higher membership degree.

According to [78], in order to aggregate fuzzy numbers $\tilde{a}$ and $\tilde{b}$, Zadeh's minimum extension principle can be applied as follows: 
$\left[f_{\lambda a+\gamma b}^{-1}(x), g_{\lambda a+\gamma b}^{-1}(x)\right]=\left[\lambda f_{a}^{-1}(x)+\gamma f_{b}^{-1}(x), \lambda g_{a}^{-1}(x)+\gamma g_{b}^{-1}(x)\right]$.

Accordingly, the following relations hold for any real numbers $\lambda$ and $\gamma$ [59]:

$M(\lambda \tilde{a}+\gamma \tilde{b})=\lambda M(\tilde{a})+\gamma M(\tilde{b})$,

$\bar{M}(\lambda \tilde{a}+\gamma \tilde{b})=\lambda \bar{M}(\tilde{a})+\gamma \bar{M}(\tilde{b})$

Possibilistic absolute deviation between any given fuzzy numbers $\tilde{a}$ and $\tilde{b}$ can be defined as follows [62]. This definition is based on mean value of fuzzy numbers proposed in [59].

$\sigma(\tilde{a}, \tilde{b})=\frac{1}{2}(\bar{M}|\tilde{a}+\tilde{b}+\bar{M}(\tilde{a})-\bar{M}(\tilde{b})|)$

The possibilistic absolute deviation can be defined for the given triangular fuzzy number $\tilde{c}$ as follows [62]:

$\sigma(\tilde{c})=\frac{1}{3}\left(c^{o}-c^{p}\right)$

The above-mentioned definitions and principles can be conveniently developed for other wellknown fuzzy numbers such as trapezoidal one (see [62]). Here, by inspiring from the ranking method of [79], we define the similar relation of fuzzy preference $\mathrm{N}(\tilde{a} ; \tilde{b})$ based on possibilistic mean values of fuzzy numbers. For any pair of fuzzy numbers $\tilde{a}$ and $\tilde{b}$, the degree of preference $\tilde{a}$ over $\tilde{b}$ or the degree in which $\tilde{a}$ is bigger than $\tilde{b}$ is defined as follows:

$$
\mu_{N}(\tilde{a}, \tilde{b})= \begin{cases}0 & \text { if } M_{2}^{a}-M_{1}^{b}<0 \\ \frac{M_{2}^{a}-M_{1}^{b}}{M_{2}^{a}-M_{1}^{b}-\left(M_{1}^{a}-M_{2}^{b}\right)} & \text { if } 0 \in\left[M_{1}^{a}-M_{2}^{b}, M_{2}^{a}-M_{1}^{b}\right] \\ 1 & \text { if } M_{1}^{a}-M_{2}^{b}>0\end{cases}
$$

Where $\left[M_{1}^{a}, M_{2}^{a}\right]$ and $\left[M_{1}^{b}, M_{2}^{b}\right]$ are the mean intervals of fuzzy numbers $\tilde{a}$ and $\tilde{b}$, respectively. When $\mu_{N}(\tilde{a}, \tilde{b}) \geq \alpha$, it is said that $\tilde{a}$ is bigger than or equal to $\tilde{b}$, at least at degree $\alpha$ and it is shown by $\tilde{a} \geq_{\alpha} \tilde{b}$.

Given two fuzzy numbers $\tilde{a}$ and $\tilde{b}$, it is stated that $\tilde{a}$ is indifferent (equal) to $\tilde{b}$ in degree of $\alpha$ if the following inequalities hold simultaneously (see [80]):

$\tilde{a} \geq_{\alpha / 2} \tilde{b}, \tilde{a} \leq_{\alpha / 2} \tilde{b}$

The above equations can be rewritten as follows: 
$\frac{\alpha}{2} \leq \mu_{N}(\tilde{a}, \tilde{b}) \leq 1-\frac{\alpha}{2}$

Considering the above-mentioned definitions and principles for mean value of fuzzy numbers, the following definitions are used in transforming a fuzzy model to its equivalent crisp model.

According to [58], a decision vector $x \in R^{n}$ is feasible in degree of $\alpha$ ( $\alpha$-feasible) if $\min _{i=1, \ldots, n}\left\{\mu_{N}\left(\tilde{a}_{i} x, \tilde{b}_{i}\right)\right\}=\alpha$. In other words, when

$\tilde{a}_{i} x \geq_{\alpha} \tilde{b}_{i}, \quad i=1, \ldots, l$

According to (B.11), it is concluded that:

$\frac{M_{2}^{a_{i} x}-M_{1}^{b_{i}}}{M_{2}^{a_{i} x}-M_{1}^{b_{i}}-\left(M_{1}^{a_{i} x}-M_{2}^{b_{i}}\right)} \geq \alpha \quad i=1, \ldots, l$

And according to principle (B.6), we have:

$\left[(1-\alpha) M_{2}^{a_{i}}+\alpha M_{1}^{a_{i}}\right] x \geq \alpha M_{2}^{b_{i}}+(1-\alpha) M_{1}^{b_{i}}, \quad i=1, \ldots, l$

The above procedure can be conveniently applied on fuzzy equalities. To do so, the fuzzy equalities must be converted to two fuzzy unequal form. Thus, when we have:

$\tilde{a}_{i} x \approx_{\alpha} \tilde{b}_{i}, \quad i=l+1, \ldots, m$

It is deduced that:

$\frac{\alpha}{2} \leq \frac{M_{2}^{a_{i} x}-M_{1}^{b_{i}}}{M_{2}^{a_{i} x}-M_{1}^{b_{i}}-\left(M_{1}^{a_{i} x}-M_{2}^{b_{i}}\right)} \leq 1-\frac{\alpha}{2} \quad i=l+1, \ldots, m$

And in accordance with (B.12), the above inequality is rewritten as follows:

$$
\begin{aligned}
& {\left[\left(1-\frac{\alpha}{2}\right) M_{2}^{a_{i}}+\frac{\alpha}{2} M_{1}^{a_{i}}\right] x \geq \frac{\alpha}{2} M_{2}^{b_{i}}+\left(1-\frac{\alpha}{2}\right) M_{1}^{b_{i}}, \quad i=l+1, \ldots, m} \\
& {\left[\frac{\alpha}{2} M_{2}^{a_{i}}+\left(1-\frac{\alpha}{2}\right) M_{1}^{a_{i}}\right] x \leq\left(1-\frac{\alpha}{2}\right) M_{2}^{b_{i}}+\frac{\alpha}{2} M_{1}^{b_{i}}, \quad i=l+1, \ldots, m}
\end{aligned}
$$

\section{Appendix C.}

Table C.1. The most likely values of biodiesel demand in different periods $\left(D_{c t}\right)$ 


\begin{tabular}{lccccccc}
\hline City\period & $\mathrm{t}=1$ & $\mathrm{t}=2$ & $\mathrm{t}=3$ & $\mathrm{t}=4$ & $\mathrm{t}=5$ & $\mathrm{t}=6$ & $\mathrm{t}=7$ \\
\hline Tabriz & 64380 & 194925 & 341400 & 344814 & 348262 & 351745 & 355262 \\
Uromieh & 67620 & 93440 & 179100 & 180891 & 182700 & 184527 & 186372 \\
Ardabil & 39240 & 54160 & 103800 & 104838 & 105886 & 106945 & 108015 \\
Isfahan & 202920 & 614675 & 1077600 & 1088376 & 1099260 & 1110252 & 1121355 \\
Bushehr & 61200 & 84600 & 162150 & 163772 & 165409 & 167063 & 168734 \\
Tehran & 296040 & 864250 & 1177800 & 1189578 & 1201474 & 1213489 & 1225623 \\
Khorasan R. & 119100 & 360950 & 632700 & 639027 & 645417 & 651871 & 658390 \\
Khozestan & 155940 & 472425 & 827700 & 835977 & 844337 & 852780 & 861308 \\
Zanjan & 31440 & 43670 & 83850 & 84689 & 85535 & 86391 & 87255 \\
Semnan & 46200 & 64100 & 123000 & 124230 & 125472 & 126727 & 127994 \\
Sistan va Balochestan & 116100 & 160750 & 308400 & 311484 & 314599 & 317745 & 320922 \\
Fars & 146460 & 443400 & 777600 & 785376 & 793230 & 801162 & 809174 \\
Gazvin & 71840 & 99510 & 190800 & 192708 & 194635 & 196581 & 198547 \\
Gom & 41460 & 57280 & 109650 & 110747 & 111854 & 112973 & 114102 \\
Kurdistan & 27780 & 38540 & 73950 & 74690 & 75436 & 76191 & 76953 \\
Kerman & 140700 & 194850 & 373500 & 377235 & 381007 & 384817 & 388666 \\
Kermanshah & 48300 & 66930 & 128550 & 129836 & 131134 & 132445 & 133770 \\
Golestan & 28440 & 39420 & 75600 & 76356 & 77120 & 77891 & 78670 \\
Gilan & 56240 & 77960 & 149550 & 151046 & 152556 & 154082 & 155622 \\
Lorestan & 33600 & 46550 & 89250 & 90143 & 91044 & 91954 & 92874 \\
Mazandaran & 56580 & 78440 & 150450 & 151955 & 153474 & 155009 & 156559 \\
Markazi & 76500 & 106000 & 203250 & 205283 & 207335 & 209409 & 211503 \\
Hormozgan & 101580 & 140560 & 269700 & 272397 & 275121 & 277872 & 280651 \\
Hamadan & 36000 & 49750 & 95250 & 96203 & 97165 & 98136 & 99118 \\
Yazd & 76740 & 106320 & 203850 & 205889 & 207947 & 210027 & 212127 \\
\hline
\end{tabular}

Table C. 2. The most likely values of glycerin demand in different period $\left(D E_{n t}\right)$

\begin{tabular}{lccccccc}
\hline Citylperiod & $\mathrm{t}=1$ & $\mathrm{t}=2$ & $\mathrm{t}=3$ & $\mathrm{t}=4$ & $\mathrm{t}=5$ & $\mathrm{t}=6$ & $\mathrm{t}=7$ \\
\hline Tabriz & 4420 & 9370 & 16260 & 16423 & 16587 & 16753 & 16920 \\
Isfahan & 4420 & 9370 & 16260 & 16423 & 16587 & 16753 & 16920 \\
Tehran & 167740 & 356470 & 619230 & 625422 & 631677 & 637993 & 644373 \\
Khorasan J. & 4420 & 9370 & 16260 & 16423 & 16587 & 16753 & 16920 \\
Khorasan R & 4420 & 9370 & 16260 & 16423 & 16587 & 16753 & 16920 \\
Khozestn & 4420 & 9370 & 16260 & 16423 & 16587 & 16753 & 16920 \\
Semnan & 8840 & 18750 & 32610 & 32936 & 33265 & 33598 & 33934 \\
Gom & 4420 & 9370 & 16260 & 16423 & 16587 & 16753 & 16920 \\
Gilan & 4420 & 9370 & 16260 & 16423 & 16587 & 16753 & 16920 \\
Markazi & 4420 & 9370 & 16260 & 16423 & 16587 & 16753 & 16920 \\
Yazd & 8840 & 18750 & 32610 & 32936 & 33265 & 33598 & 33934 \\
\hline
\end{tabular}

Table C. 3. The most likely values of UCO supply from cities in different periods $\left(W O_{g t}\right)$ 


\begin{tabular}{lccccccc}
\hline Citylperiod & $\mathrm{t}=1$ & $\mathrm{t}=2$ & $\mathrm{t}=3$ & $\mathrm{t}=4$ & $\mathrm{t}=5$ & $\mathrm{t}=6$ & $\mathrm{t}=7$ \\
\hline Tabriz & 33524 & 33928 & 34336 & 34750 & 35169 & 35592 & 36021 \\
Uromieh & 27726 & 28060 & 28398 & 28740 & 29086 & 29437 & 29791 \\
Ardabil & 11238 & 11373 & 11510 & 11649 & 11789 & 11931 & 12075 \\
Isfahan & 43918 & 44447 & 44983 & 45525 & 46073 & 46628 & 47190 \\
Ilam & 5018 & 5078 & 5140 & 5202 & 5264 & 5328 & 5392 \\
Bushehr & 9298 & 9410 & 9523 & 9638 & 9754 & 9872 & 9991 \\
Tehran & 109661 & 110983 & 112320 & 113673 & 115043 & 116429 & 117831 \\
Chahar M. B. & 8060 & 8157 & 8256 & 8355 & 8456 & 8558 & 8661 \\
Khorasan J. & 5961 & 6033 & 6105 & 6179 & 6253 & 6329 & 6405 \\
Khorasan R. & 53957 & 54607 & 55265 & 55931 & 56605 & 57287 & 57977 \\
Khorasan Sh. & 7810 & 7904 & 7999 & 8096 & 8193 & 8292 & 8392 \\
Khozestan & 40789 & 41280 & 41777 & 42281 & 42790 & 43306 & 43828 \\
Zanjan & 9144 & 9255 & 9366 & 9479 & 9593 & 9709 & 9826 \\
Semnan & 5687 & 5755 & 5825 & 5895 & 5966 & 6038 & 6110 \\
Sistan va & 22813 & 23088 & 23366 & 23648 & 23932 & 24221 & 24513 \\
Fars & 41379 & 41878 & 42382 & 42893 & 43410 & 43933 & 44462 \\
Gazvin & 10816 & 10946 & 11078 & 11212 & 11347 & 11484 & 11622 \\
Gom & 10373 & 10498 & 10625 & 10753 & 10882 & 11014 & 11146 \\
Kurdistan & 13449 & 13611 & 13775 & 13941 & 14109 & 14279 & 14451 \\
Kerman & 26455 & 26773 & 27096 & 27422 & 27753 & 28087 & 28425 \\
Kermanshah & 17512 & 17723 & 17936 & 18152 & 18371 & 18593 & 18817 \\
Kohgiluyeh & 5928 & 5999 & 6071 & 6144 & 6219 & 6293 & 6369 \\
Golestan & 15997 & 16190 & 16385 & 16582 & 16782 & 16984 & 17189 \\
Gilan & 22331 & 22600 & 22872 & 23148 & 23427 & 23709 & 23995 \\
Lorestan & 15795 & 15985 & 16178 & 16373 & 16570 & 16770 & 16972 \\
Mazandaran & 27674 & 28008 & 28345 & 28687 & 29032 & 29382 & 29736 \\
Markazi & 12729 & 12882 & 13037 & 13194 & 13353 & 13514 & 13677 \\
Hormozgan & 14208 & 14379 & 14552 & 14727 & 14905 & 15084 & 15266 \\
Hamadan & 15825 & 16016 & 16209 & 16404 & 16602 & 16802 & 17004 \\
Yazd & 9675 & 9791 & 9909 & 10029 & 10149 & 10272 & 10395 \\
\hline & & & & & & &
\end{tabular}

Table C. 4. The most likely values of JCL yields in different periods $\left(\eta_{f t}\right)$

\begin{tabular}{lccccccc} 
Citylperiod & $\mathrm{t}=1$ & $\mathrm{t}=2$ & $\mathrm{t}=3$ & $\mathrm{t}=4$ & $\mathrm{t}=5$ & $\mathrm{t}=6$ & $\mathrm{t}=7$ \\
\hline Isfahan & 5 & 14 & 15 & 15 & 15 & 15 & 15 \\
Ilam & 5 & 14 & 15 & 15 & 15 & 15 & 15 \\
Bushehr & 8.8 & 21.2 & 22.8 & 22.8 & 22.8 & 22.8 & 22.8 \\
Tehran & 5 & 14 & 15 & 15 & 15 & 15 & 15 \\
Chahar Mahaal and Bakhtiari & 5 & 14 & 15 & 15 & 15 & 15 & 15 \\
Khorasan J. & 5 & 14 & 15 & 15 & 15 & 15 & 15 \\
Khorasan R. & 5 & 14 & 15 & 15 & 15 & 15 & 15 \\
Khorasan Sh. & 5 & 14 & 15 & 15 & 15 & 15 & 15
\end{tabular}




\begin{tabular}{lccccccc} 
Khozestan & 8.8 & 21.2 & 22.8 & 22.8 & 22.8 & 22.8 & 22.8 \\
Zanjan & 5 & 14 & 15 & 15 & 15 & 15 & 15 \\
Semnan & 5 & 14 & 15 & 15 & 15 & 15 & 15 \\
Sistan va Balochestan & 8.8 & 21.2 & 22.8 & 22.8 & 22.8 & 22.8 & 22.8 \\
Fars & 5 & 14 & 15 & 15 & 15 & 15 & 15 \\
Gazvin & 5 & 14 & 15 & 15 & 15 & 15 & 15 \\
Gom & 5 & 14 & 15 & 15 & 15 & 15 & 15 \\
Kerman & 5 & 14 & 15 & 15 & 15 & 15 & 15 \\
Kermanshah & 5 & 14 & 15 & 15 & 15 & 15 & 15 \\
Kohgiluyeh and Boyer-Ahmad & 6.8 & 17 & 18 & 18 & 18 & 18 & 18 \\
Lorestan & 5 & 14 & 15 & 15 & 15 & 15 & 15 \\
Markazi & 5 & 14 & 15 & 15 & 15 & 15 & 15 \\
Hormozgan & 8.8 & 21.2 & 22.8 & 22.8 & 22.8 & 22.8 & 22.8 \\
Hamadan & 5 & 14 & 15 & 15 & 15 & 15 & 15 \\
Yazd & 5 & 14 & 15 & 15 & 15 & 15 & 15 \\
\hline
\end{tabular}

Table C. 5. The most likely values of JCL cultivation costs corresponding to the breakpoints of cultivated area in different locations $\left(V C J_{f i}\right)$

\begin{tabular}{llllll}
\hline & \multicolumn{5}{c}{ Breakpoints of cultivated area } \\
\cline { 2 - 6 } City & $\leq 50000$ & 100000 & 150000 & 200000 & $\geq 300000$ \\
\hline Isfahan & 8780000 & 17045000 & 24795000 & 32025000 & 45455000 \\
Ilam & 8600000 & 16690000 & 24275000 & 31355000 & 44505000 \\
Bushehr & 8910000 & 17295000 & 25155000 & 32490000 & 46110000 \\
Tehran & 8895000 & 17265000 & 25115000 & 32440000 & 46040000 \\
Chahar Mahaal and Bakhtiari & 8745000 & 16975000 & 24695000 & 31900000 & 45280000 \\
Khorasan J. & 8330000 & 16170000 & 23520000 & 30380000 & 43120000 \\
Khorasan R. & 8520000 & 16540000 & 24060000 & 31080000 & 44110000 \\
Khorasan Sh. & 8500000 & 16500000 & 24000000 & 31000000 & 44000000 \\
Khozestan & 8940000 & 17350000 & 25235000 & 32595000 & 46265000 \\
Zanjan & 8610000 & 16715000 & 24315000 & 31405000 & 44575000 \\
Semnan & 8675000 & 16840000 & 24495000 & 31640000 & 44910000 \\
Sistan va Balochestan & 8565000 & 16625000 & 24180000 & 31235000 & 44335000 \\
Fars & 8885000 & 17250000 & 25090000 & 32410000 & 46000000 \\
Gazvin & 8715000 & 16920000 & 24610000 & 31790000 & 45120000 \\
Gom & 8640000 & 16770000 & 24395000 & 31510000 & 44720000 \\
Kerman & 8660000 & 16810000 & 24455000 & 31590000 & 44840000 \\
Kermanshah & 8640000 & 16770000 & 24395000 & 31510000 & 44720000 \\
Kohgiluyeh and Boyer-Ahmad & 8930000 & 17335000 & 25215000 & 32570000 & 46230000 \\
Lorestan & 8845000 & 17170000 & 24975000 & 32260000 & 45790000 \\
Markazi & 8770000 & 17020000 & 24755000 & 31975000 & 45385000 \\
Hormozgan & 8620000 & 16730000 & 24335000 & 31435000 & 44615000 \\
Hamadan & 8675000 & 16840000 & 24495000 & 31640000 & 44910000 \\
& & & & &
\end{tabular}




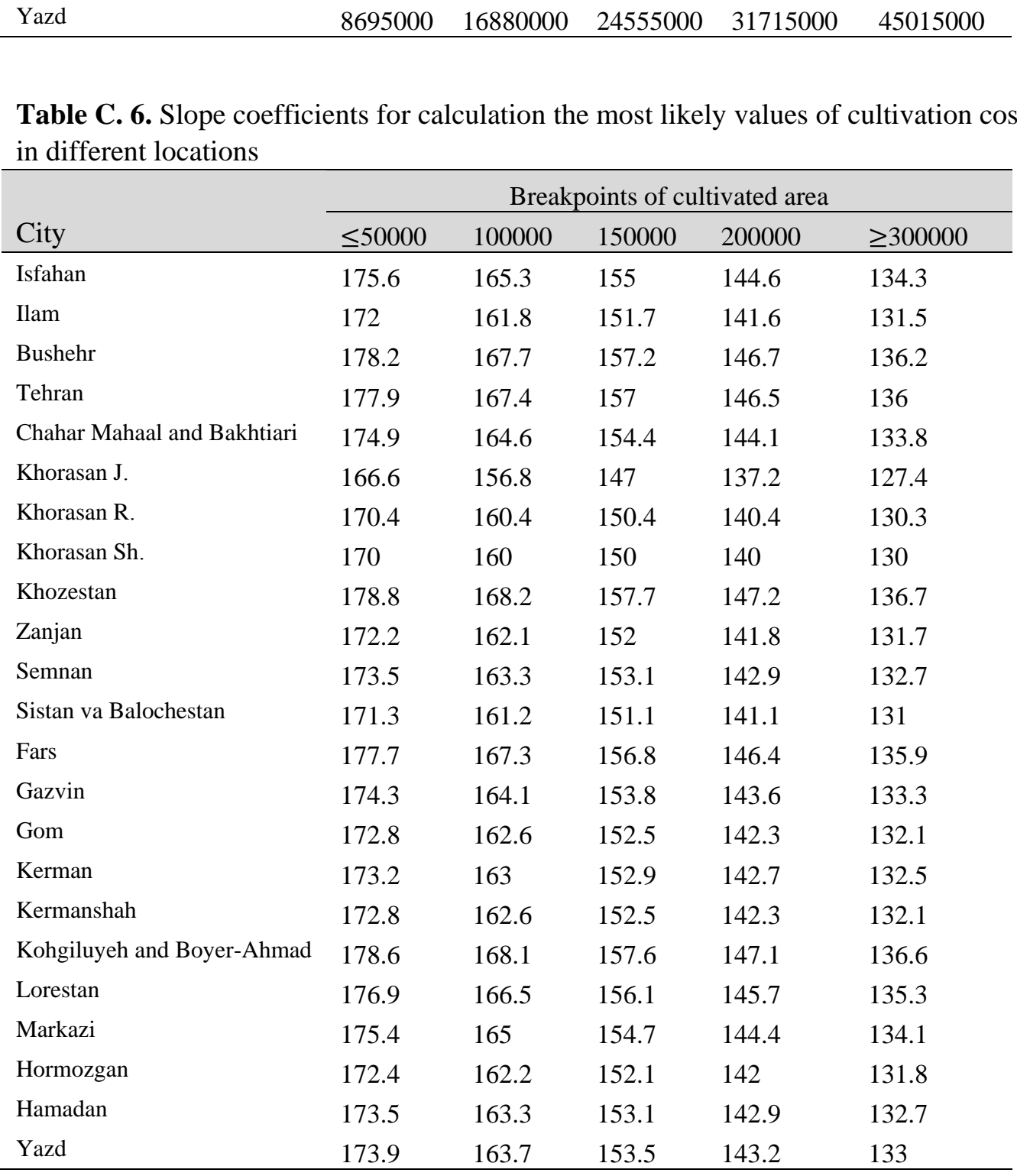

Table C. 7. The most likely values of environmental impact

\begin{tabular}{|c|c|}
\hline Parameter & Value \\
\hline$e x_{f}$ & 1554 \\
\hline$e y_{s}$ & 5.49 \\
\hline$e u_{i}$ (Cold pressing method) & 2759.99 \\
\hline$e v_{j}$ & 1853.33 \\
\hline$e w_{k}$ & 20.49 \\
\hline$E B_{j}$ (Transesterification method) & 630 \\
\hline$E G_{j}$ & 631 \\
\hline$E O_{i}$ & 1940 \\
\hline$E W_{s}$ & 46 \\
\hline$E C_{g}$ & 57 \\
\hline
\end{tabular}




\begin{tabular}{|c|c|}
\hline$E I J_{i}$ & 4.44 \\
\hline$E I W_{s}$ & 22 \\
\hline$E I B_{j}$ & 32.9 \\
\hline$E i G_{j}$ & 22 \\
\hline$E I S_{k}$ & 0.00469 (Road) \\
\hline$E J T_{f l i}$ & 0.00291 (Rail) \\
\hline$E W T_{g l s}$ & 0.00469 (Road) \\
\hline$E O T_{i l j}$ & 0.00291 (Rail) \\
\hline \multirow{2}{*}{$E V T_{s l j}$} & 0.00469 (Road) \\
\hline \multirow{2}{*}{$E B T_{j l k}$} & 0.00469 (Road) \\
\hline \multirow{2}{*}{$E C T_{j l n}$} & 0.00291 (Rail) \\
\hline \multirow{2}{*}{$E M T_{k l c}$} & 0.00469 (Road) \\
\hline$E I m_{i}$ & 0.00291 (Rail) \\
\hline & 0.00469 (Road) \\
\hline & 0.00291 (Rail) \\
\hline & 0.00469 (Road) \\
\hline
\end{tabular}

\section{References}

[1] EIA. International Energy Outlook 2008. Energy Information Administration, U.S. Department of Energy, Washingtion, D.C. 99 pp. 2008.

[2] Andersen F, Iturmend F, Espinos S, Diaz MS. Optimal design and planning of biodiesel supply chain with land competition. Computers and Chemical Engineering. 2012; 47:170-182.

[3] Zhang J, Osmani A, Awudu I, Gonela V. An integrated optimization model for switchgrass-based bioethanol supply chain. Applied Energy. 2013; 102:1205-1217.

[4] Naik SN, Goud VV, Rout PK, Dalai AK. Production of first and second generation biofuels: A comprehensive review. Renewable and Sustainable Energy Reviews. 2010; 14:578-597.

[5] Achten WMJ, Verchot L, Franken YJ, Mathijs E, Singh VP, Aerts R, Muys B. Jatropha bio-diesel production and use. Biomass and bioenergy. 2008; 32:1063-1084.

[6] Pandey VC, Singh K, Singh JS, Kumard A, Singh B, Singh RP. Jatropha curcas: A potential biofuel plant for sustainable environmental development. Renewable and Sustainable Energy Reviews. 2012; 16:28702883.

[7] Jongschaap REE, Corre Wg, Bindraban PS, Brandenburg WA. Claims and facts on Jatropha curcas L. Plant research international B.V., Wageningen; 2007.

[8] Juan JC, Kartika DA, Wu TY, Hin TY. Biodiesel production from jatropha oil by catalytic and noncatalytic approaches: an overview. Bioresour Technol. 2011; 102(2):452-60. 
[9] Silitonga AS, Atabani AE, Mahlia TMI, Masjuki HH, Badruddin IA, Mekhilef SA. Review on prospect of Jatropha curcas for biodiesel in Indonesia. Renew Sustain Energy Rev. 2011; 15(8):3733-3756.

[10] Kumar S, Chaube A, Jain SK. Sustainability issues for promotion of Jatropha biodiesel in Indian scenario: a review. Renew Sustain Energy Rev. 2012; 16(2):1089-1098.

[11] Tan KT, Lee KT, Mohamed AR. Potential of waste palm cooking oil for catalyst-free biodiesel production. Energy. 2011; 36:2085-2088.

[12] White L, Lee GJ. Operational research and sustainable development: tackling the social dimension. European Journal of Operational Research. 2009; 193:683-692.

[13] Ramos T.R.P., Gomes M.I., Barbosa-Póvoa A.P. Planning a sustainable reverse logistics system: Balancing costs with environmental and social concerns. Omega. 2014; 48: 60-74.

[14] Pishvaee MS, Torabi SA, Razmi J. Credibility-based fuzzy mathematical programming model for green logistics design under uncertainty. Computers \& Industrial Engineering. 2012; 62:624-632.

[15] Eskandarpour M., Dejax P., Miemczyk J., Péton O. Sustainable supply chain network design: An optimization-oriented review. Omega. 2015; 54: 11-32.

[16] Hugo A, Pistikopoulos EN. Environmentally conscious long-range planning and design of supply chain networks. J. Cleaner Prod. 2005; 13:1471-1491.

[17] Goedkoop M, Spriensma R. Eco-indicator 99: A Damage Oriented Method for Life Cycle Assessment, Methodology Report, third ed. PRé Consultants, Amersfoort, Netherlands; 2001.

[18] Jolliet O, Margni M, Charles R, Humbert S, Payet J, Rebitzer G, Rosenbaum R. IMPACT 2002+: a new life cycle impact assessment methodology. Int. J. Life Cycle Assess. 2003; 8(6):324-330.

[19] Goedkoop M, Heijungs R, Huijbregts M, Schryver A, Struijs J, van Zelm R. ReCiPe 2008: A Life Cycle Impact Assessment Method which Comprises Harmonised Category Indicators at the Midpoint and the Endpoint Level, Report I: Characterisation, Ministry of Housing, Spatial planning and the Environment, Netherlands; 2009.

[20] Chiu CT, Hsu TH, Yang WF. Life cycle assessment on using recycled materials for rehabilitating asphalt pavements. Resources, Conservation and Recycling. 2008; 52:545-556.

[21] Chen C-W, Fan Y. Bioethanol supply chain system planning under supply and demand uncertainties. Transp. Res. Part E Logist. Transp. Rev. 2012; 48:150-164.

[22] An H, Wilhelm WE, Searcy SW. Biofuel and petroleum-based fuel supply chain research: A literature review. Biomass Bioenergy. 2011; 35:3763-3774.

[23] Pandey A. Handbook of Plant-based Biofuels. Taylor \& Francis, Boca Raton; 2008.

[24] Papapostolou C, Kondili E, Kaldellis JK. Development and implementation of an optimisation model for biofuels supply chain. Energy. 2011; 36:6019-6026.

[25] Troncosoa JJ, Garrido RA. Forestry production and logistics planning: an analysis using mixed-integer programming. For Policy Econ. 2005; 7:625-33.

[26] Ng WPQ, Lam HL, Yusup S. Supply network synthesis on rubber seed oil utilisation as potential biofuel feedstock. Energy. 2013; 55:82-88.

[27] Rentizelas AA, Tolis AJ, Tatsiopoulos IP. Logistics issues of biomass: The storage problem and the 
multi-biomass supply chain. Renew. Sustain. Energy Rev. 2009; 13:887-894.

[28] Rentizelas A.A., Tatsiopoulos I.P. Locating a bioenergy facility using a hybrid optimization method. Int. J. Production Economics. 2010; 123: 196-209.

[29] Akgul O., Shah N., Papageorgiou L.G. An optimisation framework for a hybrid first/second generation bioethanol supply chain. Computers \& Chemical Engineering. 2012; 42:101-114.

[30] Huang Y, Chen CW, Fan Y. Multistage optimization of the supply chains of biofuels. Transp Res Part E. $2010 ; 46: 820-30$.

[31] Ebadian M, Sowlati T, Sokhansanj S, Townley-Smith L, Stumborg M. Modeling and analysing storage systems in agricultural biomass supply chain for cellulosic ethanol production. Appl. Energy. 2013; 102:840-849.

[32] Giarola S, Zamboni A, Bezzo F. Spatially explicit multi-objective optimisation for design and planning of hybrid first and second generation biorefineries. Comput. Chem. Eng. 2011; 35:1782-1797.

[33] Giarola S, Bezzo F, Nilay S. A risk management approach to the economic and environmental strategic design of ethanol supply chains. Biomass and Bioenergy. 2013; 58:31-51.

[34] Liu Z, Qiu T, Chen B. A study of the LCA based biofuel supply chain multi-objective optimization model with multi-conversion paths in China. Applied Energy. 2014; 126:221-234.

[35] Santibañez-Aguilar JE, González-Campos JB, Ponce-Ortega JM, Serna-González M, El-Halwagi MM Optimal planning and site selection for distributed multiproduct biorefineries involving economic, environmental and social objectives. Journal of Cleaner Production. 2014; 65:270-294.

[36] Cundiff JS, Dias N, Sherali HD. A linear programming approach for designing a herbaceous biomass delivery system. Bioresour. Technol. 1997; 59:47-55.

[37] Osmani A, Zhang J. Stochastic optimization of a multi-feedstock lignocellulosic-based bioethanol supply chain under multiple uncertainties. Energy. 2013; 59:157-172.

[38] Dal-Mas M, Giarola S, Zamboni A, Bezzo F. Strategic design and investment capacity planning of the ethanol supply chain under price uncertainty. Biomass Bioenergy. 2011; 35:2059-2071.

[39] Gonela V., Zhang J., Osmani A. Stochastic optimization of sustainable industrial symbiosis based hybrid generation bioethanol supply chains. Computers \& Industrial Engineering. 2015; 87: 40-65.

[40] Kim J, Realff MJ, Lee JH. Optimal design and global sensitivity analysis of biomass supply chain networks for biofuels under uncertainty. Comput. Chem. Eng. 2011; 35:1738-1751.

[41] Osmani A, Zhang J. Economic and environmental optimization of a large scale sustainable dual feedstock lignocellulosic-based bioethanol supply chain in a stochastic environment. Applied Energy. 2014; 114:572-587.

[42] Babazadeh R, Jolai F, Razmi J, Pishvaee MS. Developing a robust programming approach for the responsive logistics network design under uncertainty. International Journal of Industrial Engineering: Theory, Applications and Practice. 2014; 21(1):1-17.

[43] Gmunder S, Singh R, Pfister S, Adheloya A, Zah R. Environmental Impacts of Jatropha curcas Biodiesel in India. Journal of Biomedicine and Biotechnology. 2012; doi:10.1155/2012/623070.

[44] Fukuda H, Kondo A, Noda H. Biodiesel Fuel Production by Transesterification of Oils. Journal of Bioscience and bioengineering. 2001; 92:405-416. 
[45] Gold S, Seuring S. Supply chain and logistics issues of bio-energy production. Journal of Cleaner Production. 2011; 19:32-42.

[46] Pishvaee MS, Zanjirani Farahani R, Dullaert W. A memetic algorithm for bi-objective integrated forward/reverse logistics network design. Computers \& Operations Research. 2010; 37:1100-1112.

[47] Shen ZM. Integrated supply chain design models: A survey and future research directions. Journal of Industrial and Management Optimization. 2007; 3(1):1-27.

[48] Zhang Y, Dube MA, McLean DD, Kates M. Biodiesel production from waste cooking oil: 1. Process design and technological assessment. Bioresource Technology. 2003; 89:1-16.

[49] Yu H, Zeng AZ, Zhao L. Single or dual sourcing: decision-making in the presence of supply chain disruption risks. Omega. 2009; 37(4):788-800.

[50] Mirzapour Al-e-hashem SMJ, Baboli A, Sazvar Z. A stochastic aggregate production planning model in a green supply chain: Considering flexible lead times, nonlinear purchase and shortage cost functions. European Journal of Operational Research. 2013; 230:26-41.

[51] Li HL, Yu CS. A global optimization method for nonconvex separable programming problems. European Journal of Operational Research. 1999; 117(2):275-292.

[52] Beale EML, Tomlin JA. Special facilities in a general mathematical programming system for nonconvex problems using ordered sets of variables, in: J. Lawrence, ed., Proceedings of the fifth international conference on operational research (Tavistock Publications, London. 1970; pp. 447-454.

[53] Tomlin JA. Special Ordered Sets and an Application to Gas Supply Operations Planning. Mathematical Programming. 1988; 42:69-84.

[54] Wolsey LA. Integer programming. Wiley-Interscience publication, Series In Discrete Mathematics and Optimization, New York, USA; 1998.

[55] Beale EML, Forrest JJH. Global optimization using special ordered sets. Mathematical Programming. 1976; 10: 52-69.

[56] Babazadeh R, Rafiei H, Rabbani M. A dynamic sustainable cell formation problem in agile production systems. Int. J. Operational Research. 2013; 16(4): 448-464.

[57] Pishvaee MS, Razmi J, Torabi S. Robust possibilistic programming for socially responsible supply chain network design: A new approach. Fuzzy Sets and Systems. 2012; 206:1-20.

[58] Jiménez M, Arenas M, Bilbao A, Rodriguez MV. Linear programming with fuzzy parameters: an interactive method resolution. European Journal of Operational Research. 2007; 177:1599-1609.

[59] Carlsson C, Fullér R. On possibilistic mean value and variance of fuzzy numbers. Fuzzy Sets Syst. 2001; 122:315-326.

[60] Soleimani H, Govindan K. Reverse logistics network design and planning utilizing conditional value at risk. European Journal of Operational Research. 2014; 237:487-497.

[61] Heckmann I, Comes T, Nickel S. A Critical Review on Supply Chain Risk -Definition, Measure and Modeling. Omega. 2015; 52:119-132.

[62] Zhang P, Zhang WG. Multiperiod mean absolute deviation fuzzy portfolio selection model with risk control and cardinality constraints. Fuzzy Sets and Systems. 2014; 255:74-91. 
[63] Tang O, Musa SN. Identifying risk issues and research advancements in supply chain risk management. Int. J. Production Economics. 2011; 133(1):25-34.

[64] Mulvey JM, Vanderbei RJ, Zenios SA. Robust optimization of large-scale systems. Operations Research. 1995; 43(2):264-281.

[65] Hwang CL, Masud A. Multiple objective decision making. Methods and applications: a state of the art survey. Lecture Notes in Economics and Mathematical Systems. vol. 164. pringer-Verlag, Berlin; 1979.

[66] Mavrotas G. Effective implementation of the e-constraint method in Multi-Objective Mathematical Programming problems. Applied Mathematics and Computation. 2009; 213:455-465.

[67] Chowdhury Md.M.H., Quaddus M.A. A multiple objective optimization based QFD approach for efficient resilient strategies to mitigate supply chain vulnerabilities: The case of garment industry of Bangladesh. Omega. 2015; 57: 5-21.

[68] Ehrgott M. Multicriteria optimization, Springer, Berlin; 2005.

[69] Sahebjamnia N, Torabi SA, Mansouri SA. Integrated business continuity and disaster recovery planning: Towards organizational resiliency. European Journal of Operational Research. 2015; 242(1): 261-273.

[70] Lai YJ, Hwang CL. Possibilistic linear programming for managing interest rate risk. Fuzzy Sets and Systems. 1993; 54:135-146.

[71] Aghaei J, Amjady N, Shayanfar HA. Multi-objective electricity market clearing considering dynamic security by lexicographic optimization and augmented epsilon constraint method. Applied Soft Computing. 2011; 11:3846-3858.

[72] Azadeh A, Babazadeh R, Asadzadeh SM. Optimum estimation and forecasting of renewable energy consumption by artificial neural networks. Renewable and Sustainable Energy Reviews. 2013; 27: 605612.

[73] Van Eijck J, Romijn H, Balkema A, Faaij A. Global experience with jatropha cultivation for bioenergy: An assessment of socio-economic and environmental aspects. Renewable and Sustainable Energy Reviews. 2014; 32:869-889.

[74] Openshaw K. A review of Jatropha curcas: an oil plant of unfulfilled promise. Biomass and Bioenergy. 2000; 19:1-15.

[75] Achten WMJ. Sustainability evaluation of biodiesel from Jatropha curcas L., Belgium: PhD dissertation, Katholieke Universiteit Leuven; 2010.

[76] Babazadeh R, Razmi J. A robust stochastic programming approach for agile and responsive logistics under operational and disruption risks. Int. J. Logistics Systems and Management. 2012; 13:458-482.

[77] Pishvaee MS, Razmi J. Environmental supply chain network design using multi-objective fuzzy mathematical programming. Applied Mathematical Modelling. 2012; 36:3433-3446.

[78] Dubois D, Prade H. Operations on fuzzy numbers. International Journal of Systems. 1978; 9:613-626.

[79] Jiménez M. Ranking fuzzy numbers through the comparison of its expected intervals, International Journal of Uncertainty. Fuzziness and Knowledge Based Systems. 1996; 4(4):379-388.

[80] Parra MA, Terol AB, Gladish BP, Rodriguez Uria MV. Solving a multiobjective possibilistic problem through compromise programming. European Journal of Operational Research. 2005; 164:748-759. 